\title{
Mechanical Behavior and Application of a Novel Supporting and Retaining Structure for Slope
}

\author{
Yu Xiao ${ }^{1,2}$, Dongshuang Liu ${ }^{1,2^{*}}$, Xinrong Liu ${ }^{1,2^{*}}$, Yingkun Xie ${ }^{3,4}$, Yafeng Han ${ }^{1,2,5}$, Fei Xiong \\ 1 School of Civil Engineering, Chongqing University, Chongqing 400045, China \\ ${ }^{2}$ National Joint Engineering Research Center of Geohazards Prevention in The Reservoir Areas (Chongqing), Chongqing 400045, China \\ ${ }^{3}$ Chongqing Chuandongnan Survey \& Design Institute Co., Ltd, Chongqing 400038, China \\ ${ }^{4}$ Chongqing GaoXin Engineering Survey and Design Institute Ltd,.Co. Chongqing 401121, China \\ ${ }^{5}$ School of River \& Ocean Engineering Chongqing Jiaotong University, Chongqing 400074, China \\ *Corresponding author, e-mail: liuxrong@cqu.edu.cn; 332642300@qq.com
}

Received: 14 September 2021, Accepted: 18 February 2022, Published online: 01 March 2022

\begin{abstract}
This paper proposed a novel supporting and retaining structure used to high-steep building slope reinforcement. It combined with an anti-sliding pile and an inclined supporting column, which is used as a fulcrum on the upper part of pile. The mechanical characteristics of the novel supporting and retaining structure are studied firstly by two mechanical methods and two numerical methods, respectively. Result shows that the axial force will be evenly distributed along the column body and it provide a quite resistant force, meanwhile. There are two shear force concentrated areas of the anti-sliding pile, one is from the top of the embedded area of the pile body to the potential slip plane, the other is at the joint. Subsequently, the results of these methods are compared synthetically and the differences between the results are also discussed. It shows that a large shear force and moment will be caused at the restrained end of the pile body by the force method and 2D numerical model 1. And in Wenkler model and the 2D numerical model 2, the rock is considered non-rigid, the anti-sliding pile will produce a certain amount of deflection under the sliding thrust, which reduces the shear force and moment at the top of the embedded area of the pile body. Finally, the novel supporting and retaining structure is applied to the site, and the monitoring data shows that the novel supporting and retaining structure is economic and effective for the reinforcement of the high-steep building slope.
\end{abstract}

\section{Keywords}

high-steep building slope, novel supporting and retaining structure, mechanical characteristics, design internal force

\section{Introduction}

With the rapid development of our society, the shortage of building land is a momentous problem for our urban development. For rational development and utilization of land resources buildings may be even constructed on the highsteep slope [1-3]. Hence, the safety of buildings and highways was affected by the stability of the slope. In order to avoid the instability of slope, several slope stabilization methods was developed, which can be generally divided into anti-sliding pile system, pre-stressed system, drainage system and grouting system $[4,5]$. The anti-sliding pile system is the most conventional method to reinforce the slope. According to different landslide geological conditions, landslide scales and project requirements, the anti-sliding pile system can be divided into common anti-sliding pile (CASP), anchored anti-sliding pile (AASP) and combined pile (CP) [6-10].
CASP is the most widely used because of its simple structure and economy [11-19]. The main problem of CASP is that there is an obvious stress concentration effect occurred near slip plane, which causes high moment and large deformation of the pile. Therefore, it's ineffective for using CASP when the sliding thrust force become larger [20-22]. In order to optimize stress concentration and increase the retaining force of anti-sliding piles, AASP and CP were applied [23]. AASP is CASP combined with anchor cables on the top of piles. AASP needs stable layer to anchor the anchor cables, thus this kind of anti-sliding pile is mainly applied in rock slope.

In the recent years, some researchers have made a preliminary study on the internal force state and design parameters of AASP [24, 25]. Huang et al. [26] proposed 
a new numerical uncoupled method with more higher modeling and computing efficiency than the finite element method (FEM) for calculating the response of stabilizing piles with prestressed tie-back anchors, and using the comparative case study verified the feasibility of the method. Wu et al. [27] studied the distribution law of sliding thrust of AASP based on FLAC ${ }^{3 \mathrm{D}}$, and found that under the similar geological condition, the distribution shape of the soil pressure on the AASP would gradually change from trapezoid to rectangle when the value of pre-stress increased. Usluogullari et al. [28] used the three-dimensional (3D) finite element analysis for the comparison of slope stabilization methods including CASP and AASP, and concluded that under the investigated geological conditions using anchors to support piles reduced overall soil movements slightly more than without anchors; however, the stability coefficient $\left(F_{s}\right)$ almost remained constant comparing with using only piles. Maximum displacements decrease from 0.2 to $0.18 \mathrm{~m}$, and the soil movement at $5 \mathrm{~m}$ away from road decreases to $0.06 \mathrm{~m}$ from $0.08 \mathrm{~m}$ comparing piles supported with and without anchors, respectively.

Lately a new retaining structure of CP which called h-type anti-sliding pile was used in the southwestern mountain areas of China. The h-type anti-sliding pile is formed by a rigid combination of two rows of CASPs $[29,30]$. Zhang et al. [31] proposed the bearing and deformation analysis models. Then studied the influence rule such as the different loading conditions, pile section size, pile spacing, anchorage depth to the h-type anti-sliding pile internal force and deformation. Liu et al. [32] studied the slip plane angles, crossbeam lengths and anchor depths of the retaining mechanism and deformation response of the h-type anti-sliding pile. Qiao et al. [33] used numerical study investigated the slope failure process, the stabilization effect of the portal anti-sliding pile, and the influence mechanisms of pile parameters, and suggested that the optimum pile spacing of the portal anti-sliding pile was about twice of the length of the pile cross-section, the optimum pile row spacing of the portal anti-sliding pile was about twice of the width of the pile cross-section, and the optimum linked beam size (the size of depth direction of the pile) was about two-thirds of the pile row spacing.

The previous studies mostly focused on the AASP and h-type anti-sliding pile. However, with the ever-expanding application spectrum of the anti-sliding pile, these two types of anti-sliding pile cannot fully cater to the demands of slope reinforcement. A high-steep bedding rock slope lies Wulong district in Chongqing, China, and the stability of the slope was controlled by the dip of the weak structural plane. And two high-rise office building would be constructed on the slope, the maximum sliding thrust increased over $5000 \mathrm{kN} / \mathrm{m}$. The CASP cannot provide the required retaining force. The AASP should not be applied to the bank slope, and the anchor cable may influent the foundation of the building. Ultimately, as shown in the figure in Section 2.2, a novel supporting and retaining structure of $\mathrm{CP}$ which combined with an anti-sliding pile and a supporting column is proposed. However, the mechanical response and the internal force state of the novel supporting and retaining structure is quite different form the others.

This paper aims to study the mechanical characteristics of the novel supporting and retaining structure comprehensively. For this purpose, the mechanical characteristics of the supporting and retaining structure such as axial force, shear force, bending moment and displacement is analyzed by four different methods, such as structural mechanical force method, mechanical method based on Wenkler model, two-dimensional (2D) numerical analysis method and 3D numerical analysis method. Subsequently, the results of these four methods are compared and discussed. Based on the study results, the design internal force and structural reinforcement of supporting and retaining structure are determined. Finally, the novel supporting and retaining structure is applied in the site, and the application effect is verified by the field monitoring.

This paper is arranged as follows. Background is shown in Section 2. Methodology is described in the third Section 3. Results and discussion are performed in Section 4. Design of the internal force and application effect are presented in Section 5, and Conclusions are drawn in Section 6.

\section{Background}

The study slope lies in Chongqing China, with the height of $46 \sim 52 \mathrm{~m}$ and length of $110 \mathrm{~m}$ around, the dip angle is $40 \sim 60^{\circ}$. The rock mass of the slope is mainly limestone, and the rock mass integrity is well. A group of dominant structural plane developed in the slope with the dip of $28^{\circ}$. The mechanical parameters of slope rock and structural surface (potential slip plane) are shown in Table 1, and the mechanical parameters of structural surface are evaluated according to experience. As shown in Fig. 1, at the foot of the slope is a newly excavated artificial river with frequent water level fluctuations, and the limestone riverbed has good integrity and high strength. Two high-rise frame structure office buildings $(11 \mathrm{~F} / \mathrm{-} \mathrm{F})$ with pile foundation are planned to be built on the top of the slope, and 
Table 1 Mechanical parameters of rocks and structural plane

\begin{tabular}{lcccc}
\hline & $\begin{array}{c}\text { Saturated } \\
\text { unit weight }\end{array}$ & Cohesion & $\begin{array}{c}\text { Internal } \\
\text { friction } \\
\text { angle }\end{array}$ & $\begin{array}{c}\text { Tensile } \\
\text { strength }\end{array}$ \\
\hline Limestone & $27.0 \mathrm{kN} / \mathrm{m}^{3}$ & $600.0 \mathrm{kPa}$ & $32^{\circ}$ & $0.65 \mathrm{MPa}$ \\
$\begin{array}{l}\text { Structural plane } \\
\text { (Empirical value) }\end{array}$ & - & $50.0 \mathrm{kPa}$ & $22.6^{\circ}$ & - \\
\hline
\end{tabular}

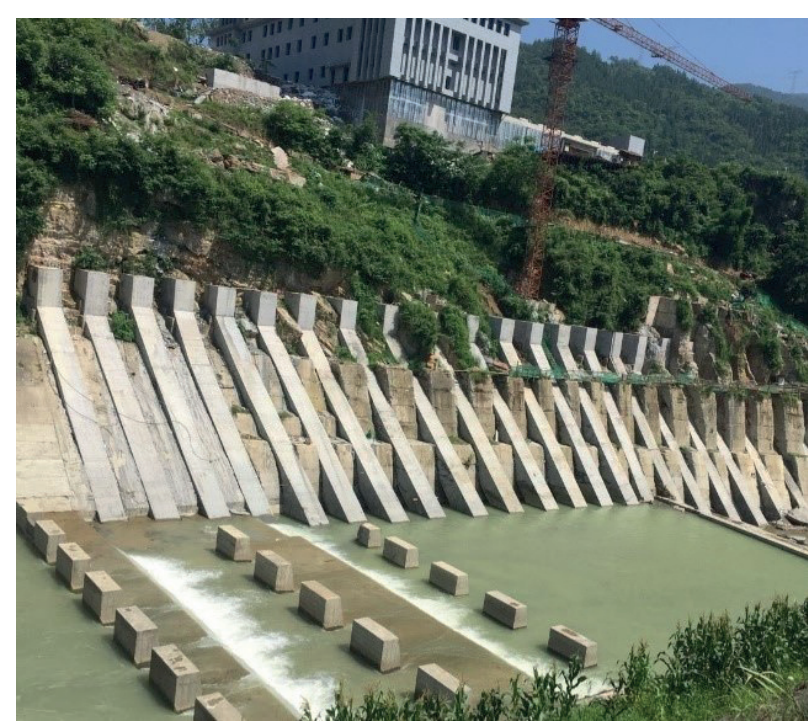

Fig. 1 Photograph of the slope (after reinforcement)

the design load of each floor is $15 \mathrm{kN} / \mathrm{m}^{2}$. In front of the buildings lies a $15 \mathrm{~m}$ wide highway, and the design lane load is $35 \mathrm{kN} / \mathrm{m}^{2}$. The safety of the buildings and highways was affected by the stability of the slope. Once the slope is deformed and damaged, it will cause huge casualties and economic losses. According to the current Technical code for building slope engineering in China [34], the safety grade of the slope is determined as grade I.

\subsection{Stability calculation of the slope}

After the building on the top of the slope is completed, the huge building load will make the slope bear a large sliding thrust. According to the theory of rock structure control, the slope may slip along the dominant structural plane. Therefore, the plane failure calculation method of slope is adopted. Considering the most unfavorable situation that the slope top simultaneously acts the maximum load (including office building load, personnel load and road load), and the A-A section directly below the building is selected for slope stability calculation. The calculation profile is shown in Fig. 2.

$F_{s}=\frac{R}{T}$

$R=(W \cos \alpha-Q \sin \alpha-V \sin \alpha-U) \tan \varphi+c l$

$T=W \sin \alpha+Q \cos \alpha+V \cos \alpha$

$V=\frac{1}{2} \gamma_{w} h_{w}^{2}$

$U=\frac{1}{2} \gamma_{w} h_{w} l$

Where $F_{s}$ is the stability coefficient, $T$ is sliding thrust and $R$ is anti-sliding force. $W$ is the total loading summed of the weight of the slide body and the loading of the building, $V$ is the fissure water pressure of the trailing edge, $U$ is the water pressure of the potential slip plane. $Q$ is the horizontal seismic force of the slide body. The slope is not in the seismic fortification zone. therefore, horizontal seismic force is not considered in this paper. $a$ is the dip of the potential slip plane, $c, \varphi$ is the cohesion and the internal friction angle of

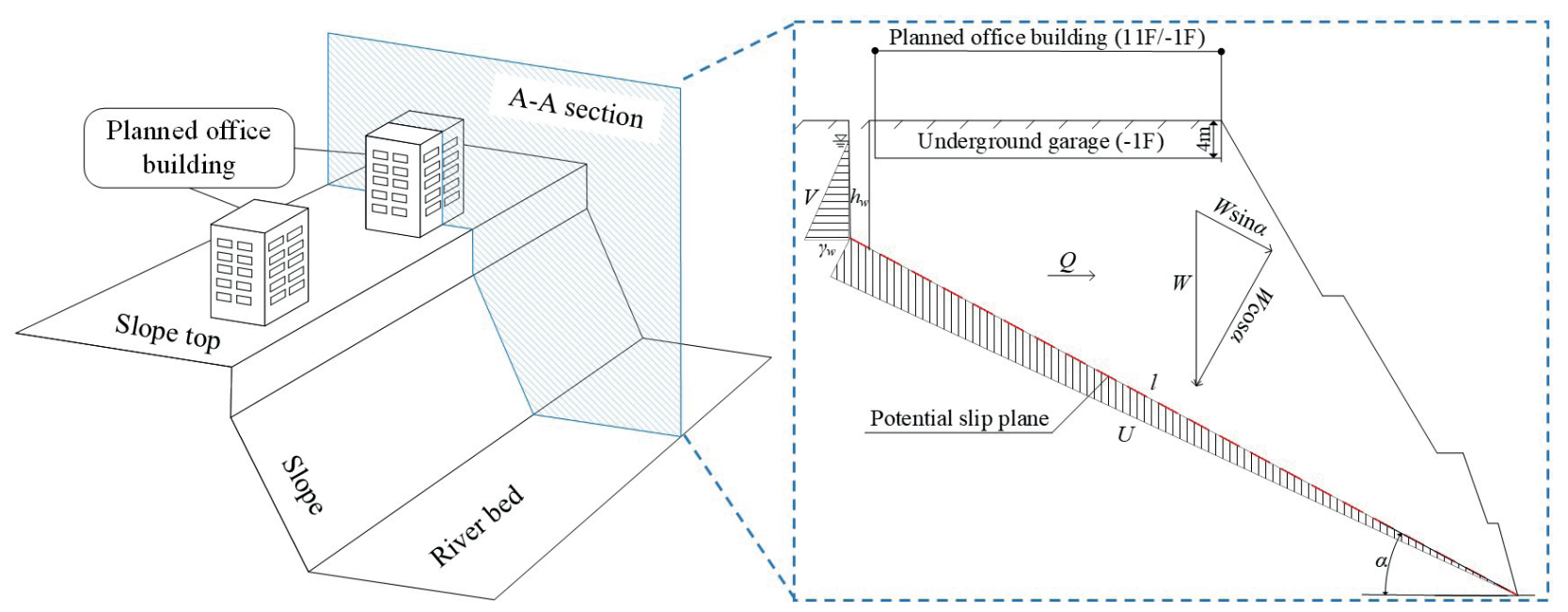

(a)

(b)

Fig. 2 Calculation model of the slope: (a) Calculation model; (b) A-A section profile 
the potential slip plane, respectively. $h_{w}$ is the height of the filling water in the fracture, the value is $1 / 2-2 / 3$ of the fracture depth. $l$ is the length of the slip plane.

\subsection{Design idea of the supporting and retaining structure}

The huge building load will make the slope bear a large sliding thrust. It is difficult for conventional retaining structure such as cantilevered anti-sliding pile to provide the required retaining force. Moreover, seasonal rainfall and upstream reservoir water transfer will cause frequent fluctuation of river water level at the foot of slope. And the prestressed anchor cable should not be used in the fluctuation zone of water level. Furthermore, the interaction of the anchorage cable and the foundation of the planned buildings should also be avoided. Thus, the application of AASP is limited. Subsequently, considering the engineering geological conditions, a novel supporting and retaining structure which combined with an anti-sliding pile and a supporting column is proposed to the slope reinforcement. The mechanism of the supporting and retaining structure can be summarized as follows: The anti-sliding pile bears the thrust of the slope, and a supporting column is used in the middle part of the cantilever area of the anti-sliding pile. As a fulcrum of the anti-sliding pile, the supporting column can provide a large resistance force for the anti-sliding pile. The bottom of supporting column extends into the bedrock of the riverbed, and most of the thrust is directly transmitted to the bedrock at the foot of slope.

As shown in Fig. 3, in the supporting and retaining structure, the rectangular sections with $3.0 \times 2.0 \mathrm{~m}^{2}$ are employed in the anti-sliding pile, and that of supporting

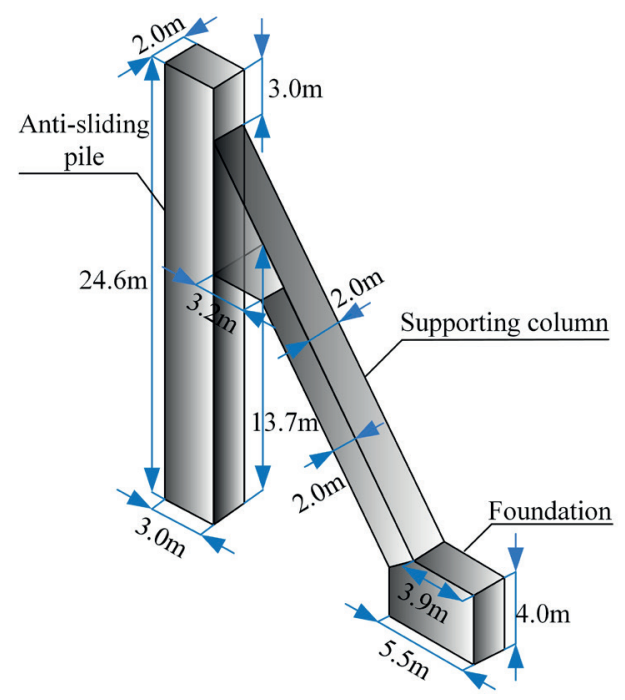

Fig. 3 Supporting and retaining structure column are $2.0 \times 2.0 \mathrm{~m}^{2}$. Both are pouring with $\mathrm{C} 30$ concrete. The embedded area of anti-sliding pile shall not be less than $8.0 \mathrm{~m}$, and that of supporting column foundation shall not be less than $4.0 \mathrm{~m}$, in which the embed to the moderately weathered limestone shall not be less than $2.5 \mathrm{~m}$.

\section{Methodology}

The mechanical response law of the supporting and retaining structure under the lateral thrust of the slope is not clear due to the great difference between the form of the supporting and retaining structure and the conventional retaining structure and the less practical use. Therefore, this paper intends to study the mechanical response characteristics of the supporting and retaining structure by means of structural mechanics force method, mechanical analysis method based on Wenkler model and FEM.

\subsection{Structural mechanical force method}

The residual sliding thrust of the rock mass above the potential slip plane of the slope is $F$, and the dip of slip plane is $28^{\circ}$. The residual sliding thrust $F$ direct effect to the part above the slip plane of Anti-sliding pile, thus it is called the direct bearing area in this paper. The $8 \mathrm{~m}$ range at the bottom of the anti-sliding pile is called the embedded area, and rest of it is cantilever area. The calculation model of supporting and retaining structure is shown in Fig. 4(a). When using the force method to analyze the mechanical response characteristics of the supporting and retaining structure, the anti-sliding pile and the supporting column are simplified as the bar structure, the joint of the anti-sliding pile and the supporting column is regarded as the rigid connection, the embedded area of the anti-sliding pile is simplified as the fixed constraint, and the bottom constraint of the supporting column is supported by the fixed hinge. Besides, the vertical component of sliding thrust $F$ is ignored in the calculation, and the horizontal component force $f$ is assumed rectangular uniform distribution on a single pile. The simplified supporting and retaining structure calculation model is shown in Fig. 4(b).

The restraint of the bottom of the supporting column is equivalent to applying a horizontal force $x_{1}$ and a vertical force $X_{2}$ at the end of it. And the bottom of supporting column is in static equilibrium under the action of $X_{1}, X_{2}$ and $f$, namely, the horizontal displacement $\Delta h$ and vertical displacement $\Delta \mathrm{v}$ at the bottom of the supporting column are zero (Fig. 4(b)). From this, displacement Eqs. (1) and (2) can be obtained. The horizontal (or vertical) displacement component caused by unknown force can be obtained 


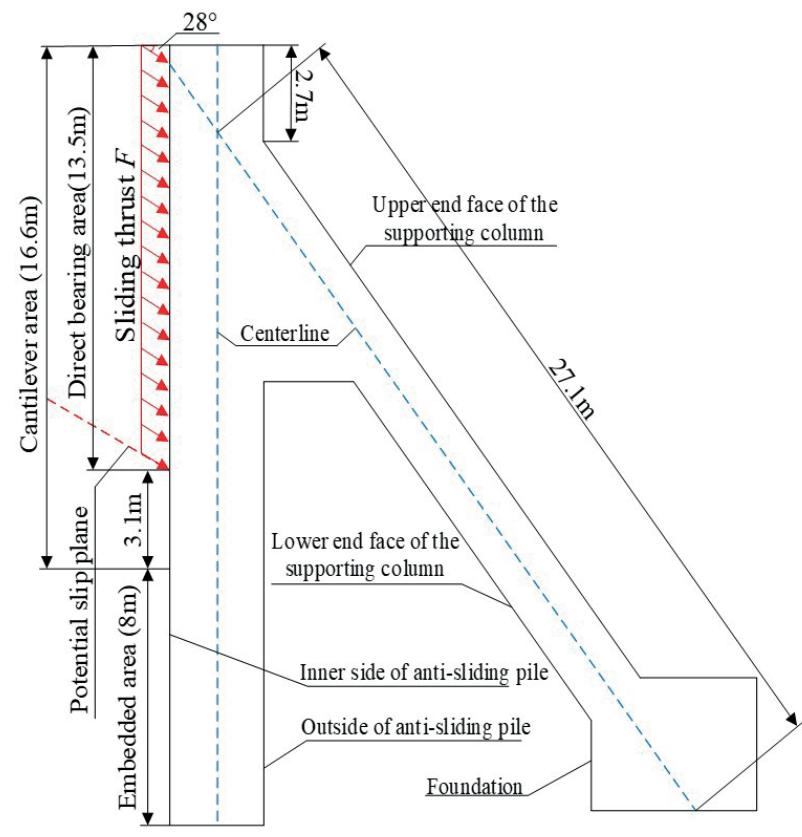

(a)

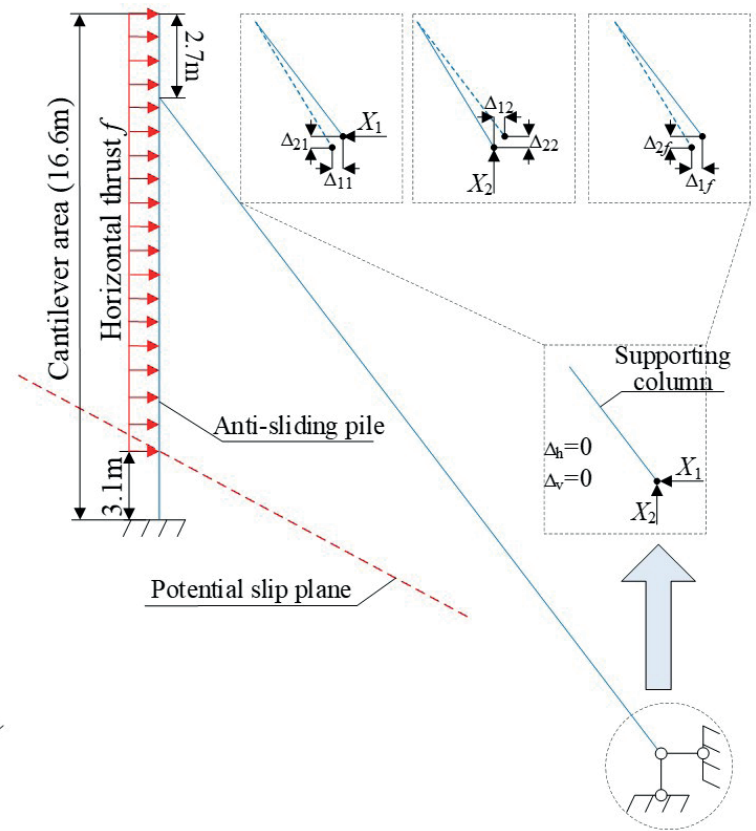

(b)

Fig. 4 Calculation model of supporting and retaining structure based on force method: (a) calculation model; (b) Simplified calculation model

by Eq. (3), then Eq. (3) are introduced into Eqs. (1) and (2), respectively, and the basic force method Eqs. (4) and (5) of the supporting and retaining structure can be obtained. Furthermore, the calculation parameters of the structural mechanical force method are listed in Table 2.

$$
\begin{aligned}
& \Delta_{h}=\Delta_{11}+\Delta_{12}+\Delta_{1 f}=0 \\
& \Delta_{v}=\Delta_{21}+\Delta_{22}+\Delta_{2 f}=0 \\
& \Delta_{i j}=\delta_{i j} X_{j} \\
& \Delta_{h}=\delta_{11} X_{1}+\delta_{12} X_{2}+\Delta_{1 f}=0 \\
& \Delta_{v}=\delta_{21} X_{1}+\delta_{22} X_{2}+\Delta_{2 f}=0
\end{aligned}
$$

Where $\Delta_{11}$ and $\Delta_{12}$ are horizontal and vertical displacements at the bottom of the supporting column when $X_{1}$ acts alone. $\Delta_{21}$ and $\Delta_{22}$ are horizontal and vertical displacements at the bottom of the supporting column when $X_{2}$ acts alone. $\Delta_{1 f}$ and $\Delta_{2 f}$ are horizontal and vertical displacements at the bottom of the supporting column when $\mathrm{f}$ acts alone. The unknown forces $X_{1}$ and $X_{2}$ can be obtained by

Table 2 Calculation parameters of the structural mechanical force method

\begin{tabular}{lccc}
\hline $\begin{array}{l}\text { Length of the } \\
\text { anti-sliding pile }\end{array}$ & $\begin{array}{c}\text { Length of the } \\
\text { supporting column }\end{array}$ & $\begin{array}{c}\text { Pile-column } \\
\text { angle }\end{array}$ & $\begin{array}{c}\text { Horizontal } \\
\text { thrust } f\end{array}$ \\
\hline $16.6 \mathrm{~m}$ & $27.1 \mathrm{~m}$ & $37.5^{\circ}$ & $4939.2 \mathrm{kN} / \mathrm{m}$ \\
\hline
\end{tabular}

the above Eqs. (6)-(10), then, the internal force diagram of the supporting and retaining structure can be drawn by the superposition principle.

\subsection{Mechanical analysis method based on Wenkler model}

The Series Software of Lizheng Geological Structure Designing [35] can quickly and accurately calculate the internal force and displacement of the pile under the action of sliding thrust. In this paper, this software is used to analyze the mechanical characteristics of the supporting and retaining structure. As shown in Fig. 5(a), the anti-sliding pile is selected as the analysis object, and the supporting column is simplified as a fulcrum B on the pile. The linear stiffness and action direction of the fulcrum are consistent with the actual supporting column. No preload is applied to the fulcrum, and the calculation is based on the rigidity of the pile and the supporting column, and meets the conditions of coordinated deformation. During the calculation process, the foundation is regarded as an elastic medium. Based on the Wenkler elastic foundation beam, the $K$ method with constant foundation coefficient is used to calculate the internal force and displacement of the pile. In addition, only the horizontal component $f$ of the sliding thrust $F$ is considered in the calculation, and it is assumed that $f$ is rectangular uniform distribution. The top of anti-sliding pile is not applied with anchor bolt (cable). Thus, it is regarded as cantilever pile. While the depth 
of embedded area is small, the constraint of pile bottom is regarded as fixed hinge support. (Fig. 5(b)) Eq. (11) is a matrix equation for calculating the internal force and displacement of anti-sliding pile. The displacement and internal force of any section of pile can be calculated by substituting boundary conditions Eqs. (12) and (13) into Eq. (11). And, the calculation parameters of the mechanical analysis method based on Wenkler model are listed in Table 3.

$\left[\left[K_{Z}\right]+\left[K_{T}\right]+\left[K_{T 0}\right]\right]\{\delta\}=\{p\}$

Boundary conditions:

Top of the anti-sliding pile: $M=0 \quad Q=0$

Bottom of the anti-sliding pile: $M=0 \quad x=0$

Where $\left[K_{Z}\right]$ is the elastic stiffness matrix of anti-sliding pile. $\left[K_{T}\right]$ is the elastic stiffness matrix of the rock (soil) below the slip plane. $\left[K_{T 0}\right]$ is the initial elastic stiffness matrix of rock (soil) below the slip plane. $\{\delta\}$ is the displacement matrix of anti-sliding pile. $\{P\}$ is the load matrix of anti-sliding pile. $M$ is moment. $Q$ is shear force. $x$ is displacement.

\subsection{FEM based on 2D numerical model}

The supporting column and anti-sliding pile in the supporting and retaining structure are simplified as the bar structure, and the 2D numerical model is calculated by ANSYS. The mechanical response characteristics of the supporting and retaining structure under the action of the sliding thrust are analyzed. The simulation is carried out in two parts. In the first one, a numerical model, which is completely consistent with the size and boundary constraints in Fig. 4(b), is established by 2D elastic beam element. The reliability of the FEM calculation results is verified by comparing the difference between the $2 \mathrm{D}$ elastic beam element numerical model and the force method, and the calculation model is shown in Fig. 6(a). After testing the reliability of the FEM results, the second part is as follows: For more truly reflect the fixed effect of the stratum on the anti-sliding pile, as shown in Fig. 6(b), the spring element (combin14) is arranged along the normal direction of the anti-sliding pile embedded area to simulate the fixed effect of the stratum on the anti-sliding pile. The length of $2 \mathrm{D}$

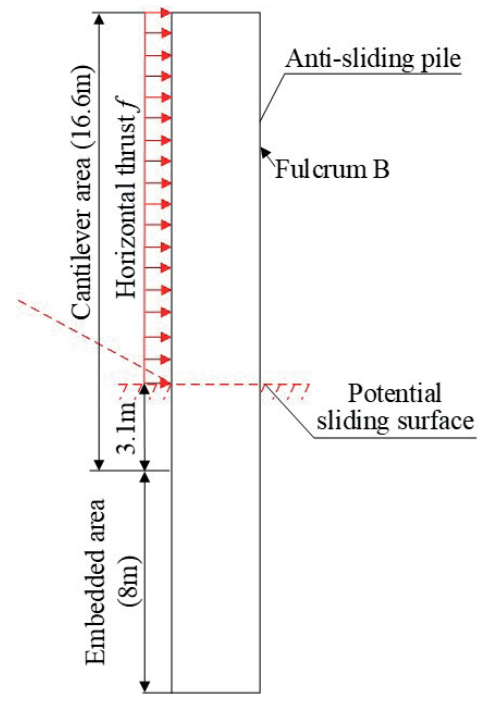

(a)

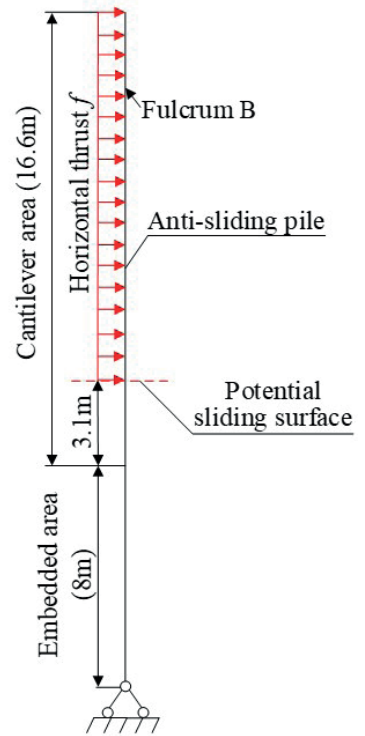

(b)
Fig. 5 Calculation model of supporting and retaining structure based on Wenkler model: (a) Calculation model; (b) Simplified calculation model

beam element numerical model is the same with center line of supporting and retaining structure, and the section size is consistent with the actual retaining structure. In addition, in the two parts of the calculation, it is assumed that the sliding thrust $F$ is rectangular uniformly distributed with the dip of $28^{\circ} . F$ acts on the cantilever area above the slip plane of the anti-sliding pile. The joint of anti-sliding pile and supporting column is regarded as rigid connection, and the end restraint of supporting column is supported by fixed hinge. The axial force, shear force and moment of the 2D beam element numerical model can be obtained by Eqs. (14)-(16). Additionally, the calculation parameters of the FEM based on 2D numerical model are listed in Table 4.

$$
\begin{aligned}
& N=\sigma^{d i r} A \\
& Q=\tau^{d i r} A \\
& M=\frac{2 I \sigma^{b n d}}{t}
\end{aligned}
$$

Where $N$ is the axial force; $\sigma^{d i r}$ is the axial stress; $A$ is the cross-sectional area of the beam. $Q$ is the shear force; $\tau^{d i r}$ is the tangential stress. $M$ is the moment; $\sigma^{\text {bnd }}$ is the bending stress; $t$ is the rigidity of the beam; $I$ is the moment of inertia of the beam section.

Table 3 Calculation parameters of the mechanical analysis method based on Wenkler model

\begin{tabular}{lcccc}
\hline $\begin{array}{l}\text { Length of the } \\
\text { anti-sliding pile }\end{array}$ & Embedded depth & Foundation coefficient & Horizontal thrust $f$ & $\begin{array}{c}\text { Counterforce of the } \\
\text { fulcrum B }\end{array}$ \\
\hline $24.6 \mathrm{~m}$ & $8 \mathrm{~m}$ & K method & $4939.2 \mathrm{kN} / \mathrm{m}$ & $13482.1 \mathrm{kN}$ \\
\hline
\end{tabular}




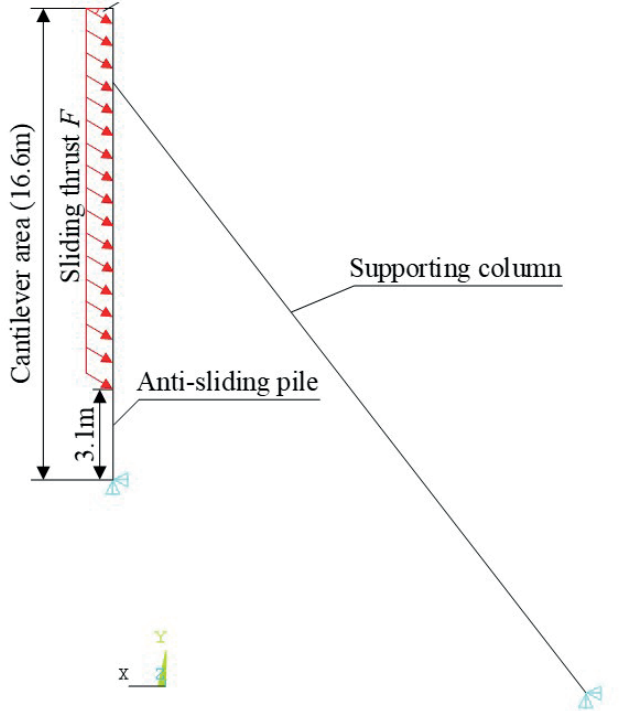

(a)

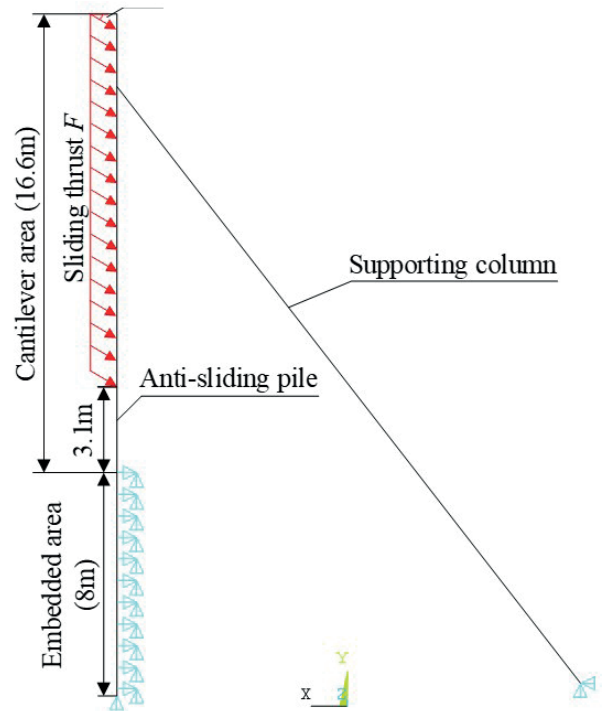

(b)

Fig. 6 Numerical model of supporting and retaining structure based on 2D elastic beam element: (a) 2D numerical model 1; (b) 2D numerical model 2

Table 4 Calculation parameters of the FEM based on 2D numerical model

\begin{tabular}{|c|c|c|c|c|c|c|c|c|c|}
\hline & $\begin{array}{l}\text { Length of the } \\
\text { anti-sliding } \\
\text { pile }\end{array}$ & $\begin{array}{l}\text { Embedded } \\
\text { depth }\end{array}$ & $\begin{array}{l}\text { Length of the } \\
\text { supporting } \\
\text { column }\end{array}$ & $\begin{array}{l}\text { Pile-column } \\
\text { angle }\end{array}$ & $\begin{array}{l}\text { Sliding } \\
\text { thrust } F\end{array}$ & $\begin{array}{c}\text { Beam } \\
\text { section }\end{array}$ & $\begin{array}{l}\text { Density of } \\
\text { the structure }\end{array}$ & $\begin{array}{l}\text { Elastic } \\
\text { modulus }\end{array}$ & $\begin{array}{l}\text { Poisson's } \\
\text { ratio }\end{array}$ \\
\hline $\begin{array}{l}\text { 2D numerical } \\
\text { model } 1\end{array}$ & $16.6 \mathrm{~m}$ & - & $27.1 \mathrm{~m}$ & $37.5^{\circ}$ & $5350 \mathrm{kN} / \mathrm{m}$ & $3 \times 2 \mathrm{~m}$ & $2551 \mathrm{~kg} / \mathrm{m}^{3}$ & $\begin{array}{c}3 \times 10^{5} \\
\mathrm{MPa}\end{array}$ & 0.2 \\
\hline $\begin{array}{l}2 \mathrm{D} \text { numerical } \\
\text { model } 2\end{array}$ & $24.6 \mathrm{~m}$ & $8 \mathrm{~m}$ & $27.1 \mathrm{~m}$ & $37.5^{\circ}$ & $5350 \mathrm{kN} / \mathrm{m}$ & $3 \times 2 \mathrm{~m}$ & $2551 \mathrm{~kg} / \mathrm{m}^{3}$ & $\begin{array}{c}3 \times 10^{5} \\
\mathrm{MPa}\end{array}$ & 0.2 \\
\hline
\end{tabular}

\subsection{FEM based on 3D numerical model}

The 3D numerical model can simulate the boundary conditions and the actual mechanical characteristics of the supporting and retaining structure more realistically. Therefore, as shown in Fig. 7(b), the 3D numerical model is established by 3D solid element (Solid65) in ANSYS, and the mechanical response characteristics of the supporting and retaining structure under the action of the sliding thrust are analyzed. The fixed effect of the stratum on the anti-sliding pile is simulated by applying a normal spring constraint to the four sides and a vertical displacement constraint to the bottom of the embedded area of the anti-sliding pile. Normal displacement constraint is applied to each side around the foundation. The size of the calculation model is consistent with the actual size of the supporting and retaining structure. Moreover, it is assumed that the sliding thrust $F$ is rectangular uniformly distributed with the dip of $28^{\circ}$. The stress and displacement values of solid elements and joints can be obtained easily in ANSYS, but the axial force, shear force and moment of solid elements cannot be displayed in it. Therefore, based on the idea of discrete summation, 11 typical calculation sections are selected in this paper, and each calculation section is divided into several small quadrilaterals. The internal force of the whole calculation section can be obtained by calculating and summating the internal force value of each small quadrilateral [36]. Eqs. (17)-(19) are the calculation formulas of the axial force, shear force and moment of the section, respectively. The location of each internal force calculation sections is shown in Fig. 7(b). Mover, the calculation parameters of the FEM based on 3D numerical model are listed in Table 5.

$$
\begin{aligned}
& N=\sum_{i}^{n}\left(\int_{A^{\prime}} \sigma(x, y) d A^{\prime}\right) \\
& Q=\sum_{i}^{n}\left(\int_{A^{\prime}} \tau(x, y) d A^{\prime}\right) \\
& M=\sum_{i}^{n}\left[\left(\int_{A^{\prime}} \sigma(x, y) d A^{\prime}\right) l\left(x_{c i}, y_{c i}\right)\right]
\end{aligned}
$$

Where $N$ is the axial force; $\sigma(x, y)$ is the axial stress. $A$ is the area of quadrilateral; $Q$ is the shear force; $\tau(x, y)$ is the tangential stress. $M$ is the moment; $l\left(x_{c i}, y_{c i}\right)$ is the distance from the action point of resultant force of the integral area to the neutral axis. 


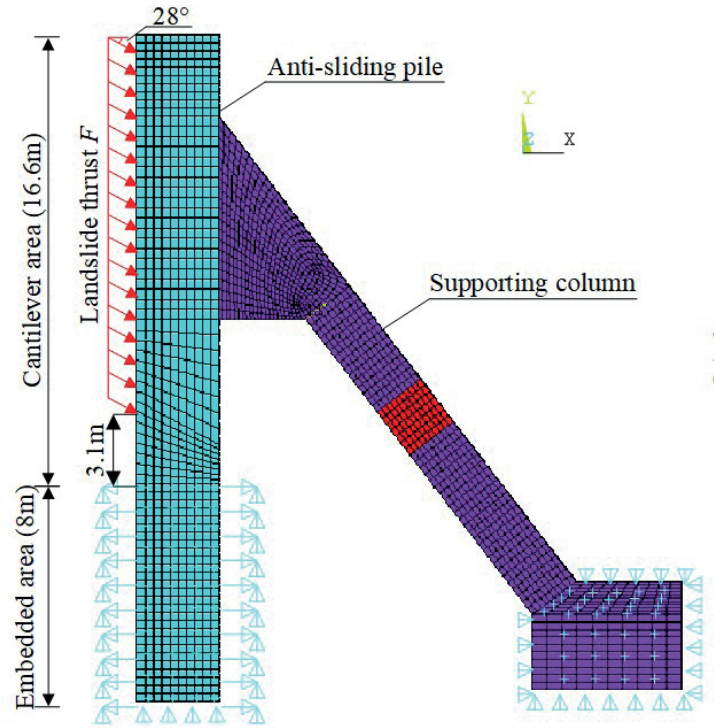

(a)

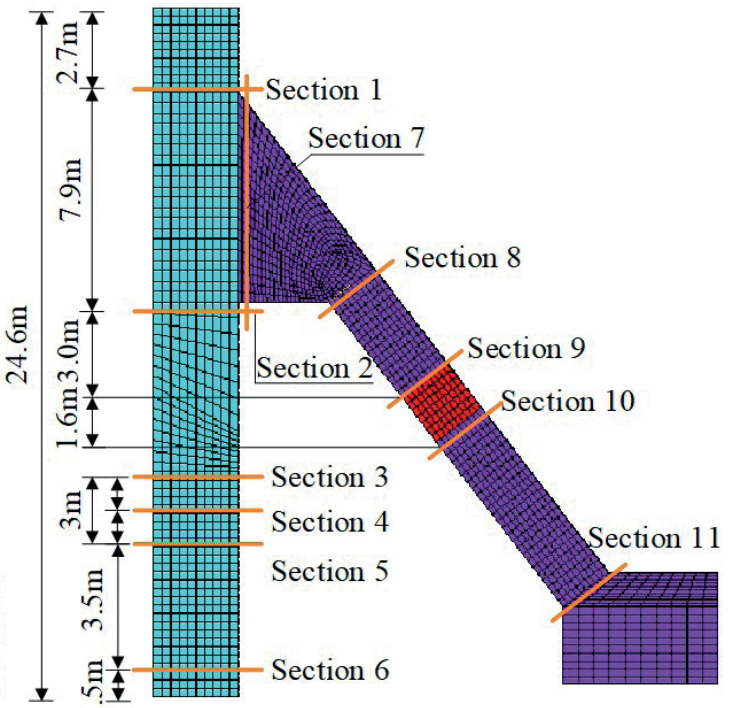

(b)

Fig. 7 Numerical model of supporting and retaining structure based on 3D solid element: (a) 3D numerical model; (b) Location of the calculation sections

Table 5 Calculation parameters of the FEM based on 3D numerical model

\begin{tabular}{lcccccc}
\hline $\begin{array}{l}\text { Length of the } \\
\text { anti-sliding pile }\end{array}$ & $\begin{array}{c}\text { Embedded } \\
\text { depth }\end{array}$ & $\begin{array}{c}\text { Length of the } \\
\text { supporting column }\end{array}$ & $\begin{array}{c}\text { Pile-column } \\
\text { angle }\end{array}$ & Sliding thrust $F$ & $\begin{array}{c}\text { Density of the } \\
\text { structure }\end{array}$ & $\begin{array}{c}\text { Elastic } \\
\text { modulus }\end{array}$ \\
\hline $24.6 \mathrm{~m}$ & $8 \mathrm{~m}$ & $27.1 \mathrm{~m}$ & $37.5^{\circ}$ & $5350 \mathrm{kN} / \mathrm{m}$ & $2551 \mathrm{~kg} / \mathrm{m}^{3}$ & $3 \times 10^{5} \mathrm{MPa}$ \\
\hline
\end{tabular}

\section{Results and discussion}

\subsection{Results of each method}

\subsubsection{Results of structural mechanical force method}

The internal force distribution of the supporting and retaining structure based on the force method is shown in Fig. 8. Under the horizontal thrust $f$, the whole supporting column is in compression state, and the axial force is evenly distributed along the column, which is $-17187.3 \mathrm{kN}$. The shear force along the supporting column also presents the characteristics of uniform distribution, which is $9.4 \mathrm{kN}$. The moment gradually increases from the bottom of the supporting column to the top i.e., the joint with the anti-sliding pile, and the maximum value is $253.3 \mathrm{kN} \cdot \mathrm{m}$. The upper end face of the supporting column is under tension and the lower it is under pressure.
Taking the joint with the supporting column as the boundary, the anti-sliding pile can be divided into two parts as compression and tension. The pile body above the joint is in compression state, and the pile body below the joint is in tension state. The axial force of the pile body at the joint is the largest, with the maximum value of $11633.7 \mathrm{kN}$. There are two shear force concentrated areas in the anti-sliding pile: In the analysis of force method, the embedded area of anti-sliding pile is simplified as fixed constraint. Therefore, under the lateral thrust of slope, a pretty shear force will be produced near the fixed constraint point, which is the first shear force concentrated area with a peak shear of $-9427.2 \mathrm{kN}$. Besides, the resistance provided by the supporting column against the sliding pile is opposite to the sliding thrust, therefore the shear at the joint is also large,

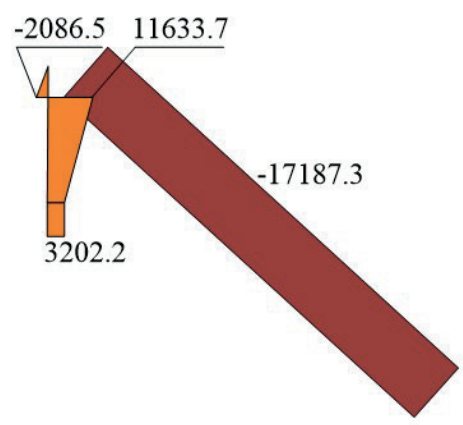

(a)

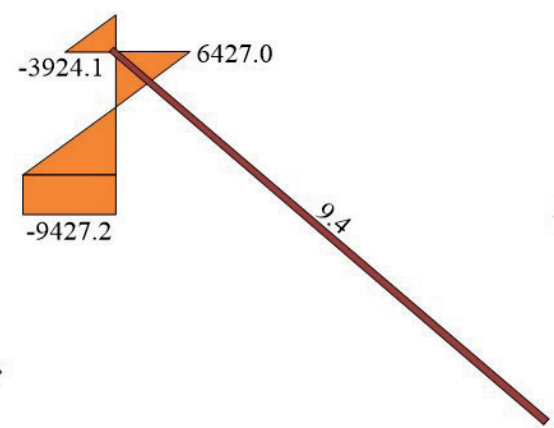

(b)

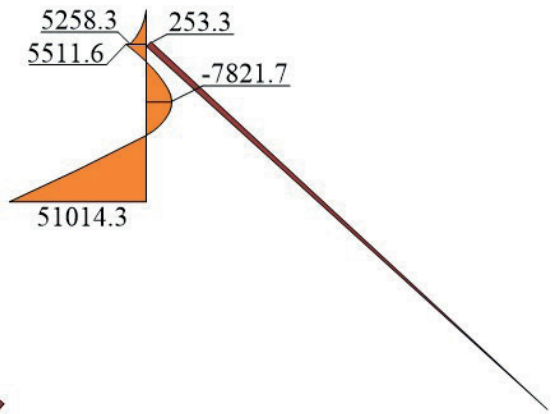

(c)

Fig. 8 Internal force distribution of supporting and retaining structure based on force method: (a) Axial force /kN; (b) Shear force /kN; (c) Moment/kN·m 
which is the second shear concentration area with the peak shear of $6427.0 \mathrm{kN}$. In the two shear force concentrated areas in the anti-sliding pile, the stirrup should be added to improve the ability of resist the shear failure. Under the sliding thrust, influenced by the resistance of the supporting column and the fixed constraint of the embedded area, a trend of turning or moving away from the slope direction will be caused in the joint to the position close and the restraint end of the pile body. The stress state of these two areas are internal tension and external compression with peak moments of $5511.6 \mathrm{kN} \cdot \mathrm{m}$ and $51014.3 \mathrm{kN} \cdot \mathrm{m}$, respectively. The middle part of the pile body is less affected by the resistance of the supporting column and the fixed constraint of the embedded area. The pile body will produce a migration trend (bulge) away from the direction of the slope under the sliding thrust. The stress state of the middle part of the pile body is internal compression and external tension, with peak moment of $-7821.7 \mathrm{kN} \cdot \mathrm{m}$.

\subsubsection{Results of mechanical method based on Wenkler model}

Fig. 9(a) is the shear distribution curve of anti-sliding pile. As it shown that there are also two shear force concentrated areas of anti-sliding pile which consistent with the result of force method. One of them extends from the top of the embedded area to the potential slip plane, i.e., the CD section in Fig. 9(a). The shear force is evenly distributed along the CD section, with the size of $-5915.2 \mathrm{kN}$. The other is at the joint, i.e., Fulcrum B in Fig. 10(a), with peak shear force of $9549.5 \mathrm{kN}$.
Fig. 9(b) is the moment distribution curve of anti-sliding pile. The figure shows that the moment at the top of embedded area calculated by Wenkler model is obviously smaller than that calculated by force method. The maximum moment of the embedded area moves down to 5.2 $\mathrm{m}$ from the pile bottom, and the peak is $13800 \mathrm{kN} \cdot \mathrm{m}$. The moment in the middle of the pile calculated by the Wenkler model is obviously larger than that calculated by the force method. The peak moment in the middle of the pile shaft is $-25885 \mathrm{kN} \cdot \mathrm{m}$, which is $4.4 \mathrm{~m}$ above the potential slip plane.

Fig. 9(c) is the displacement distribution curve of anti-sliding pile. The deformation and rotation of the pile top are limited by the resistance of the supporting column. Therefore, the horizontal displacement of the pile top is only $6.8 \mathrm{~mm}$. And the maximum horizontal displacement of the anti-sliding pile lies $5.4 \mathrm{~m}$ above the potential slip plane, which is $10.4 \mathrm{~mm}$.

\subsubsection{Results of FEM based on 2D numerical model}

Fig. 10 is the internal force contours of the supporting and retaining structure which is obtained by simplifying the constraint condition into fixed constraint of embedded area. The whole supporting column is in compression state, and the axial force is evenly distributed along the column, with the value of $-17900 \mathrm{kN}$. The shear force and moment of the supporting column are negligible.

Taking the joint with the supporting column as the boundary, the anti-sliding pile can be divided into two parts as compression and tension. The pile body above the joint is in compression state, and the pile body below the

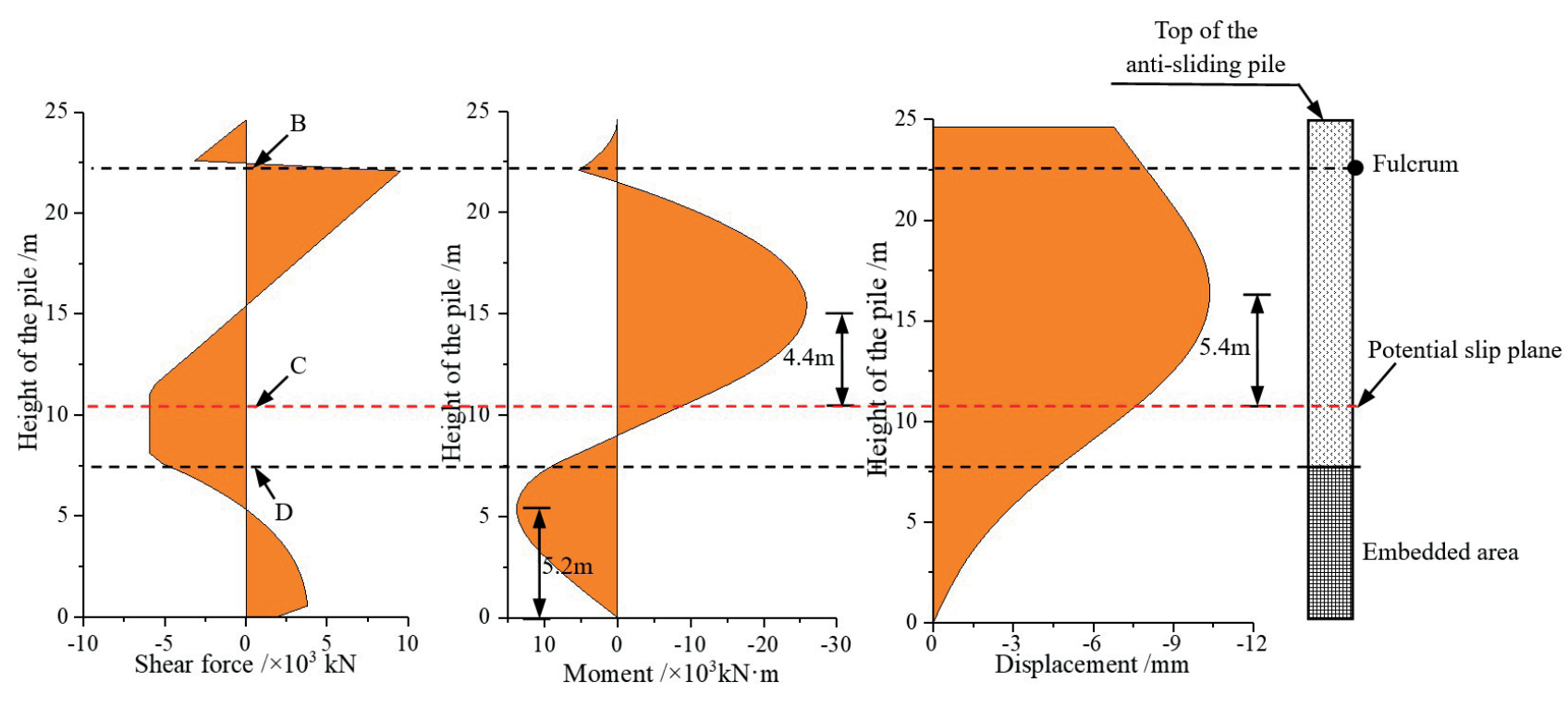

(a)

(b)

(c)

Fig. 9 Internal force distribution of anti-sliding pile based on Wenkler model: (a) Shear force $/ \times 10^{3} \mathrm{kN}$; (b) Moment $/ \mathrm{kN} \cdot \mathrm{m}$; (c) Displacement $/ \mathrm{mm}$ 


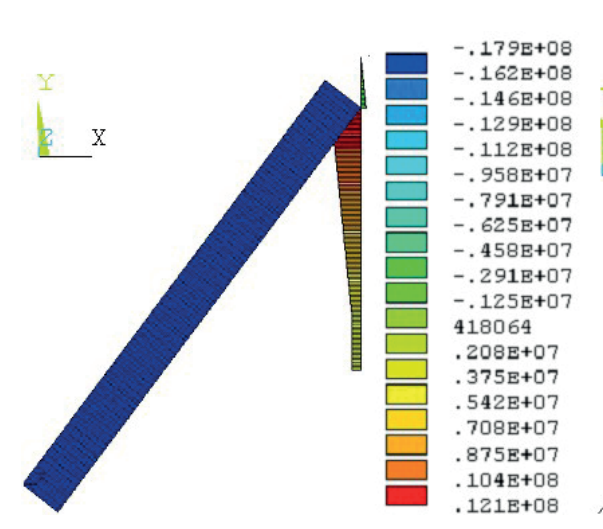

(a)

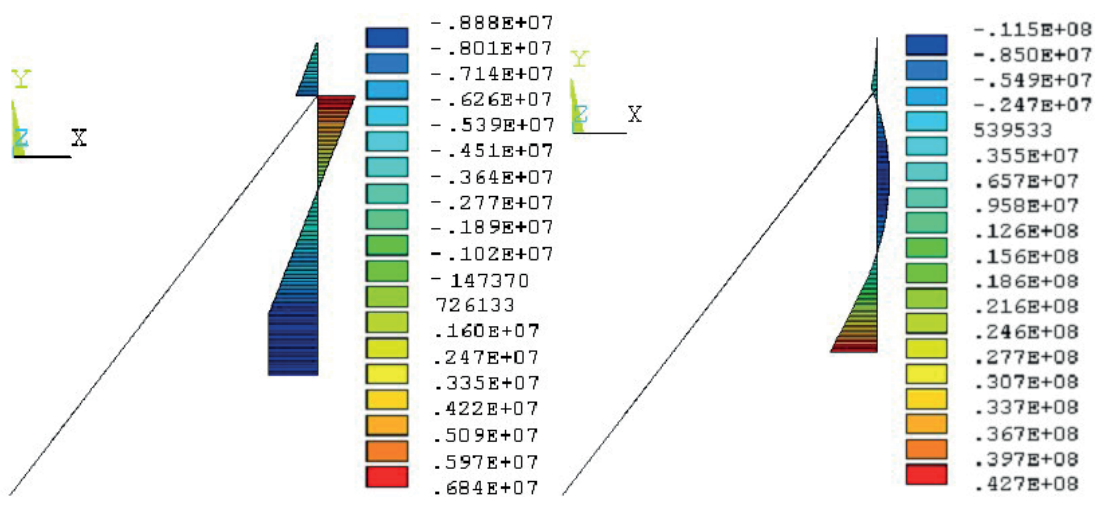

(b) (c)

Fig. 10 Internal force contours of the supporting and retaining structure with fixed hinge constraint: (a) Shear force $/ \times 10^{3} \mathrm{kN}$; (b) Moment $/ \mathrm{kN} \cdot \mathrm{m}$; (c) Displacement $/ \mathrm{mm}$

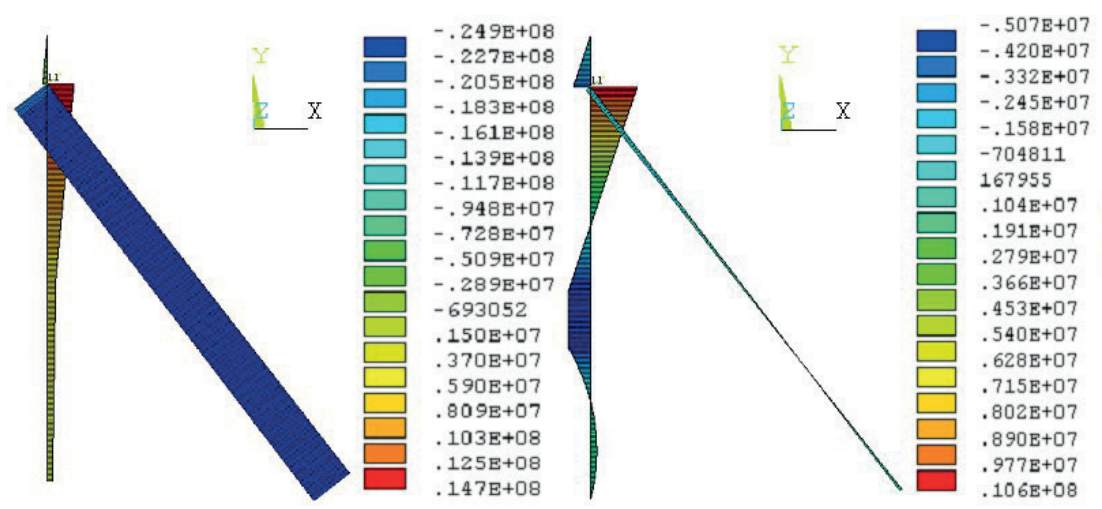

(a) (b)

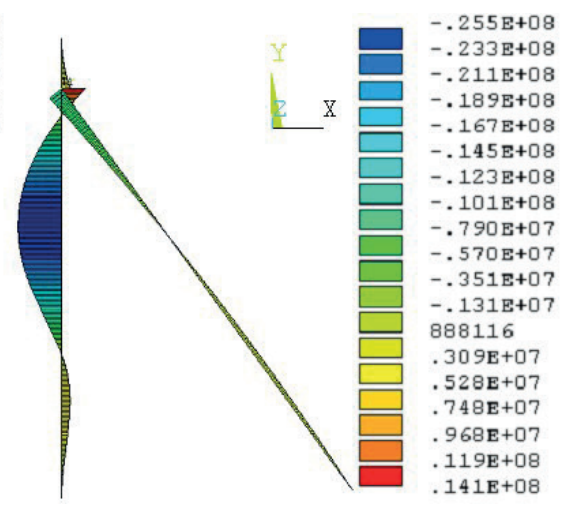

(c)

Fig. 11 Internal force contours of the supporting and retaining structure with spring constraint of embedded area: (a) Shear force $/ \times 10^{3} \mathrm{kN}$; (b)

Moment $/ \mathrm{kN} \cdot \mathrm{m}$; (c) Displacement $/ \mathrm{mm}$

joint is in tension state. The maximum axial force of the pile body at the joint is $12100 \mathrm{kN}$. The result of FEM shows that there are two shear concentration areas in the pile body, one is near the fixed constraint point of anti-sliding pile, with the peak of $-8880 \mathrm{kN}$. The other is at the joint, and the peak value is $6840 \mathrm{kN}$. The maximum moment of the anti-sliding pile is $42700 \mathrm{kN} \cdot \mathrm{m}$, which is near the embedded area of the pile body. Overall, the internal force distribution characteristics of the supporting and retaining structure calculated by the FEM constructed by the 2D elastic beam element are basically consistent with the results calculated by the force method. Accordingly, it is feasible to use the 2D elastic beam element model by FEM to analyze the mechanical characteristics of the supporting and retaining structure.

After verifying the feasibility of the 2D elastic beam element model, the mechanical characteristics of the supporting and retaining structure is analyzed. The method of setting spring element (combin14) along the normal direction of the embedded area is used to simulate the fixed effect of the stratum, and more realistic model is established.
As shown in Fig. 11, the whole supporting column is in compression state, and the axial force is evenly distributed along the column body, with the value of $-24900 \mathrm{kN}$. The maximum moment of the supporting column is 5700 $\mathrm{kN} \cdot \mathrm{m}$, which is located at the joint. The upper end face of the supporting column is under tension and the lower end face is under compression. The shear force of the supporting column is negligible.

Taking the joint with the supporting column as the boundary, the anti-sliding pile can be divided into two parts as compression and tension. The pile body above the joint is in compression state, and the pile body below the joint is in tension state. The maximum axial force of the pile body at the joint is $14700 \mathrm{kN}$. There are also two shear concentration areas in the pile body, one is near the fixed constraint point of anti-sliding pile, with the peak of $-5070 \mathrm{kN}$. The other is at the joint, and the peak value is $10600 \mathrm{kN}$. The maximum moment of the anti-sliding pile is $-25500 \mathrm{kN} \cdot \mathrm{m}$, which is near the potential slip plane. And the stress state of this area is internal compression and external tension. In addition, the moment at the top of 
the embedded area and joint area of the anti-sliding pile is also large, which is $5280 \mathrm{kN} \cdot \mathrm{m}$ and $14100 \mathrm{kN} \cdot \mathrm{m}$, respectively. And the stress state of this area is internal tension and external compression.

\subsubsection{Results of FEM based on 3D numerical model}

Fig. 12(a) is the maximum principal stress contours of the supporting and retaining structure based on the solution of the 3D finite element model. The maximum compressive stress is at the position where the geometry changes in the upper area of the supporting column, i.e., zone I in Fig. 13(a). Besides, the compressive stress in zone $\mathrm{J}$ (the upper end face of the lower area of the supporting column)
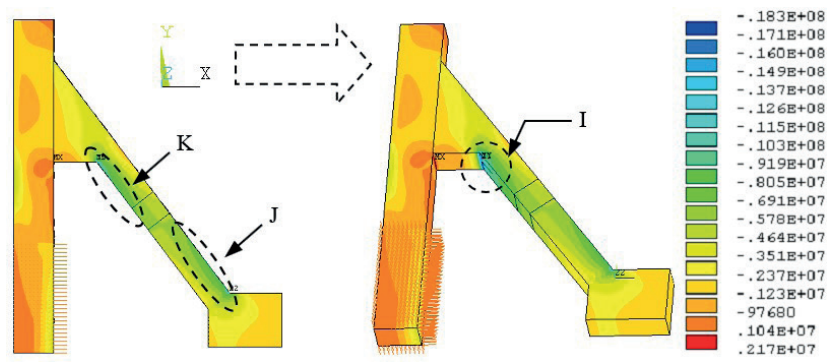

(a)

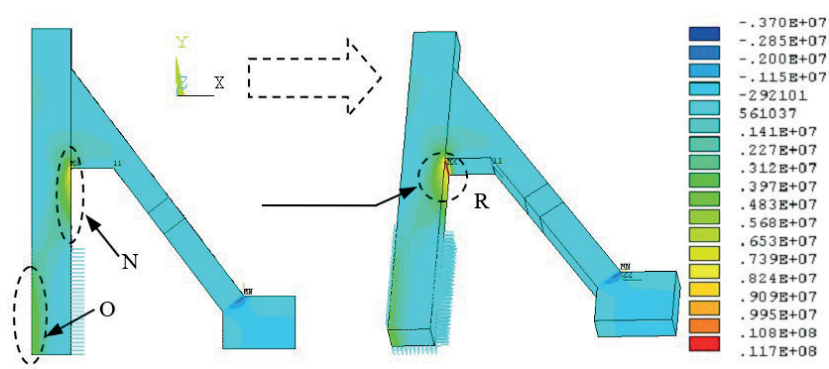

(b)

Fig. 12 Internal force contours of the supporting and retaining structure based on 3D numerical model: (a) Maximum principal stress /Pa;

(b) Minimum principal stress $/ \mathrm{Pa}$ and the zone $\mathrm{K}$ (the lower end face of the upper area of the supporting column) are also large. Fig. 12(a) is the minimum principal stress contours of the supporting and retaining structure based on the solution of the 3D finite element model. It shows that the maximum tensile stress of the supporting and retaining structure is located at the lower end face of the joint, i.e., zone R in Fig. 13(b). And, the tensile stress in the zone $\mathrm{O}$ on the inner side of the pile and the zone $\mathrm{N}$ near the joint are also large. In the reinforcement step for the supporting and retaining structure, the stress concentration area (such as tension stress concentration area $\mathrm{R}, \mathrm{N}, \mathrm{O}$, compression stress concentration area I, J, $\mathrm{K}$ ), in which longitudinal reinforcement shall be added to avoid tension (compression) damage of the structure.

The internal force of different sections by calculation method of discrete summation based on the 3D FEM results is shown in Table 6. Fig. 7(b) is the location of these calculation sections.

\subsection{Discussion}

\subsubsection{Mechanical characteristics of supporting and retaining structure}

Although there are differences in the internal force states of the supporting and retaining structure obtained by different calculation methods, the mechanical characteristics of it are consistent. Under the sliding thrust, the supporting column will bear a large axial pressure, and the axial force will be evenly distributed along the column body. The shear force is also uniform distribution along the supporting column. The moment gradually increases from the bottom to the top of the column (i.e., the joint with the anti-sliding pile), and the upper end face of the supporting column is under tension and the lower end face is under compression.

Table 6 Internal force of the supporting and retaining structure based on the 3D numerical model

\begin{tabular}{lcccccccc}
\hline Section & $F_{x} / \mathrm{kN}$ & $F_{y} / \mathrm{kN}$ & $F_{z} / \mathrm{kN}$ & $M_{x} / \mathrm{kN} \cdot \mathrm{m}$ & $M_{y} / \mathrm{kN} \cdot \mathrm{m}$ & $M_{z} / \mathrm{kN} \cdot \mathrm{m}$ & Axial force $/ \mathrm{kN}$ & Shear force $/ \mathrm{kN}$ \\
\hline 1 & 5065.9 & -3161.6 & $\min$ & $\min$ & $\min$ & -4343.4 & -3161.6 & -5065.9 \\
2 & -1003.0 & -5978.7 & $\min$ & $\min$ & $\min$ & -18438.1 & 5978.7 & 1003.0 \\
3 & -4581.2 & -2872.6 & $\min$ & $\min$ & $\min$ & 2327.1 & 2872.6 & -4581.2 \\
4 & -2652.3 & -2639.9 & $\min$ & $\min$ & $\min$ & 7939.9 & 2639.9 & -2652.3 \\
5 & -1377.1 & -2407.8 & $\min$ & $\min$ & $\min$ & 10997.5 & 2407.8 & -1377.1 \\
6 & 107.6 & 1760.1 & $\min$ & $\min$ & $\min$ & -13389.8 & -1760.1 & 107.6 \\
7 & -14701.3 & 15969.0 & $\min$ & $\min$ & $\min$ & 13193.5 & -14701.3 & 15969.0 \\
8 & -14701.3 & 17013.9 & $\min$ & $\min$ & $\min$ & - & -22241.4 & 3304.4 \\
9 & -14701.3 & 17430.8 & $\min$ & $\min$ & $\min$ & - & -22513.4 & 3620.3 \\
10 & -14701.3 & 17668.5 & $\min$ & $\min$ & $\min$ & - & -22668.5 & 3800.5 \\
11 & -14701.3 & 18409.2 & $\min$ & $\min$ & $\min$ & - & -23151.7 & 4361.9 \\
\hline
\end{tabular}


Under the sliding thrust, the anti-sliding pile can be divided into two parts: compression part and tension part. The part above the joint is in compression state, and the part below the joint is in tension state. The axial force of the pile at the joint is the largest. There are two shear force concentrated areas of the anti-sliding pile, one is from the top of the embedded area of the pile body to the potential slip plane, the other is at the joint. In the two shear force concentrated areas, the stirrup should be added to improve the ability of resist the shear failure. The maximum moment of the anti-sliding pile occurs at the area near the potential slip plane, and pile body is internal compression and external tension. In addition, the moment at the top of the embedded area and joint area of the anti-sliding pile is also large, and the stress state of this area is internal tension and external compression.

The deformation and rotation of the pile top are limited by the resistance of the supporting column. Therefore, the horizontal displacement of the pile top is only $6.8 \mathrm{~mm}$. The maximum horizontal displacement of the anti-sliding pile lies $5.4 \mathrm{~m}$ above the potential slip plane of the slope, which is $10.4 \mathrm{~mm}$.

Moreover, compared with CASP, it can provide greater resistance force and smaller deformation and rotation of the pile top. Compared with AASP, the inclined supporting column is constructed outside slope to avoid the influence of anchor cable inside slope on building pile foundation, and it is facilitated maintenance. Compared with the h-type anti-sliding pile, the inclined supporting column uses less material and reduces amount of excavation work.

\subsubsection{Comparison and analysis of results}

Fig. 13 is the comparative analysis curve of internal force of the anti-sliding pile, and Table 7 lists the internal force of the supporting column obtained by different calculation methods.

As shown in Fig. 13 and Table 7, the internal force of the supporting and retaining structure calculated by the 2D numerical model 1 is basically the same as that calculated by the force method, which shows that it is feasible to use 2D FEM model to analyze the mechanical characteristics of the supporting and retaining structure.

According to Fig. 13(b) and Fig. 13(c), the internal force distribution characteristics of the pile obtained by Wenkler model and 2D numerical model 2 are consistent. However, there are some differences in the force value, which is caused by neglecting the vertical component of the sliding thrust in Wenkler model.

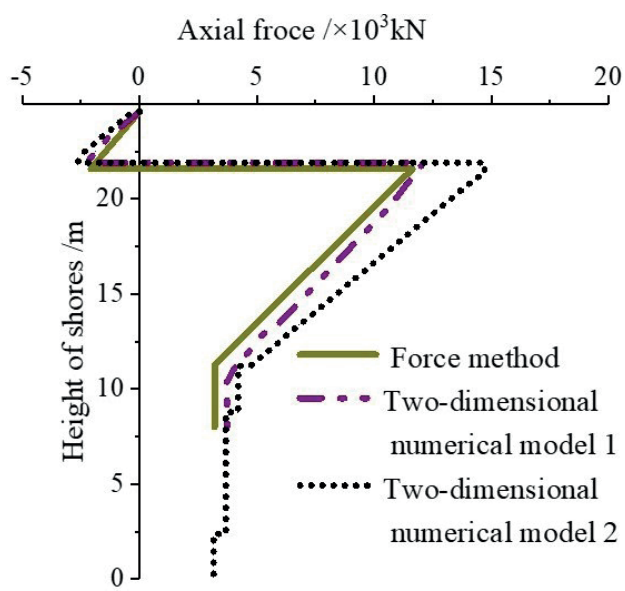

(a)

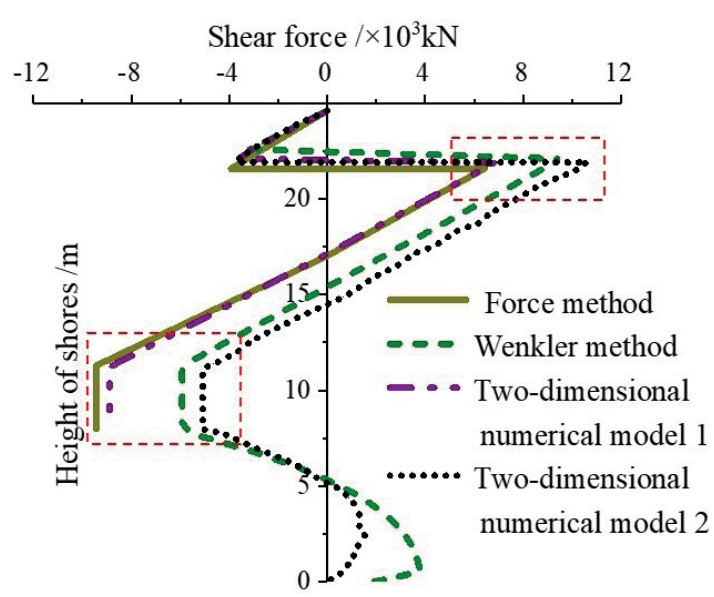

(b)

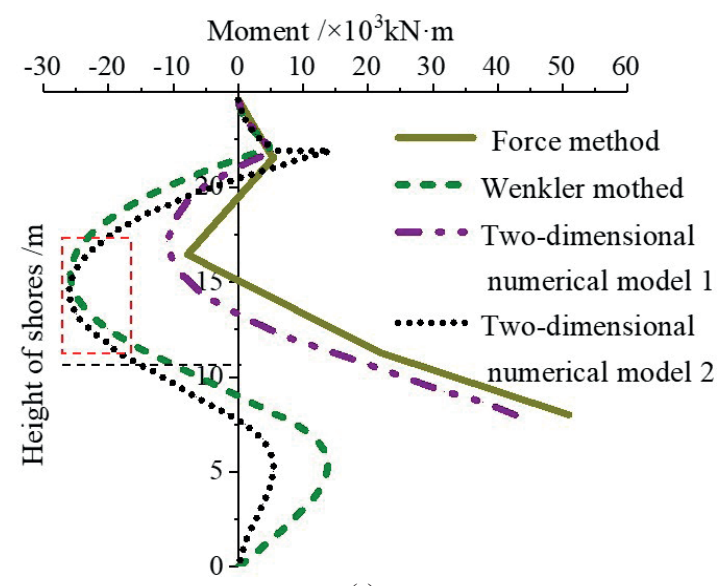

(c)

Fig. 13 Comparative analysis of internal force results of anti-sliding pile: (a) Axial force; (b) Shear force; (c) Moment

Table 7 Results comparison of internal force of supporting column

\begin{tabular}{lccc}
\hline & $\begin{array}{c}\text { Axial force } \\
/ \mathrm{kN}\end{array}$ & Shear $/ \mathrm{kN}$ & $\begin{array}{c}\text { Moment } / \\
\mathrm{kN} \cdot \mathrm{m}\end{array}$ \\
\hline Force method & -17187.3 & 9.4 & 253.3 \\
2D numerical model 1 & -17900.0 & $\min$ & $\min$ \\
2D numerical model 2 & -24900.0 & $\min$ & 5700.0 \\
3D numerical model & -23151.7 & 4361.9 & - \\
\hline
\end{tabular}


According to Fig. 13(b) and Fig. 13(c), the results obtained by force method and 2D numerical model 1 are quite different from those obtained by Wenkler model and $2 \mathrm{D}$ numerical model 2 . The reason is the different simplified methods of the embedded area of the anti-sliding pile. The embedded area is simplified as a fixed constraint by the force method and 2D numerical model 1 . The cantilever area will move along the direction of sliding thrust, but the constraint reaction provided by the fixed constraint will resist it. Thus, a large shear force and moment will be caused at the restrained end of the pile body. The constraint of pile bottom is regarded as a fixed hinge support which can rotate by the Wenkler model and 2D numerical model 2. For the rock in the embedded area is nonrigid, the anti-sliding pile will produce a certain amount of deflection under the sliding thrust, which reduces the shear force and moment at the top of the embedded area of the pile body. Besides, the moment in the middle part of the pile body are increased. Therefore, in the Wenkler model and the 2D numerical model 2, the simplified method of the embedded area is more consistent with the actual mechanical characteristics of anti-sliding pile, while in the force method and the 2D numerical model 1 , errors will be caused by simplifying the embedded area to a fixed constraint.

In the 3D numerical model, the constraint imposed on the end of the supporting column is not consistent with the real constraint condition, which makes a maximum moment distributed on the supporting column. Therefore, the value of this moment is false and should not be referent in design. In addition to the moment distribution of the supporting column, the distribution of other internal forces is basically consistent with the results of structural mechanics calculation.

\section{Design of the internal force and application}

Fig. 14 is the design internal force of the supporting and retaining structure. The supporting column is under compressive stress, and the maximum axial force is $-24900 \mathrm{kN}$ by result of $2 \mathrm{D}$ numerical model 2 . The maximum shear force of the supporting column is $4361.9 \mathrm{kN}$ which above the foundation by result of 3D numerical model. Therefore, the design axial force and shear force of the supporting column are $-25000 \mathrm{kN}$ and $4361.9 \mathrm{kN}$, respectively.

The design axial force and shear force of the anti-sliding pile is $9000 \mathrm{kN}$ based on the result of 3D numerical model. Because the joint of the supporting column and the anti-sliding pile are all simplified to a point in the other methods, and it cause an unreal axial force near the joint. The design shear force of the anti-sliding pile is $-7000 \mathrm{kN}$ at the potential slip plane based on the result of the Wenkler model. Because the embedded area is simplified to fixed constraint in the force method and the 2D numerical model 1. The design moment of the anti-sliding pile is -27000 $\mathrm{kN} \cdot \mathrm{m}$ based on the 2D numerical model 2 .

The longitudinal reinforcement is 13 bundles C32 in the pile and 13 bundles $\mathrm{C} 28$ in the column. The stirrup is C12@300(6) in the pile and C12@150(6) in the column. The tensile stress of the abrupt change of geometry at the lower part of the joint is large. Therefore, longitudinal reinforcement shall be provided at there. The shear force near the slip plane, the bottom of the pile and the upper and lower ends of the supporting column are large. Therefore, the stirrup densification area is set at the above parts.

As shown in Fig. 15, the novel supporting and retaining structure are applied in the slope reinforcement successfully. And the supporting and retaining structure numbered B4 and B12, which is directly below the office building, is selected as the monitoring object to detect

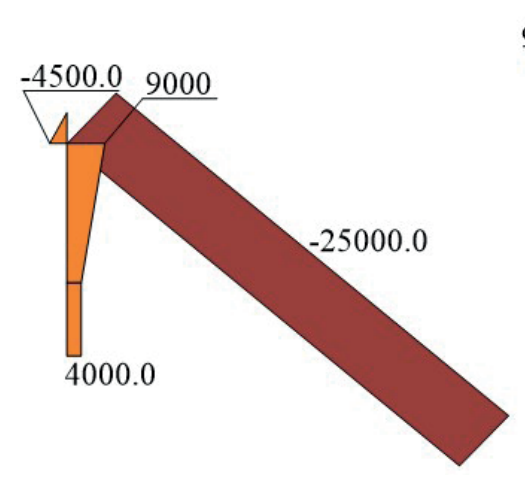

(a)

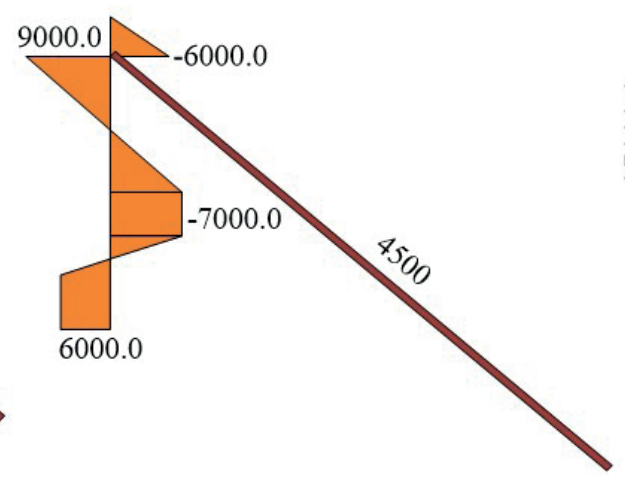

(b)

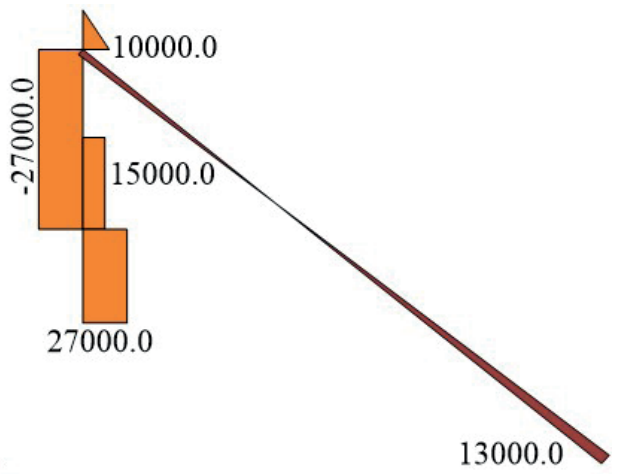

(c)

Fig. 14 Design force of supporting and retaining structure: (a) Axial force $/ \mathrm{kN}$; (b) Shear force $/ \mathrm{kN}$; (c) Moment $/ \mathrm{kN} \cdot \mathrm{m}$ 


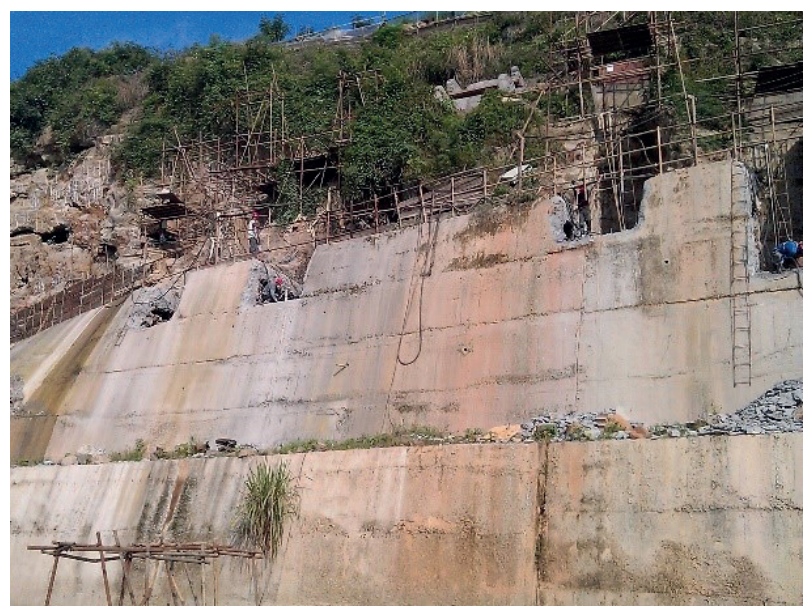

(a)

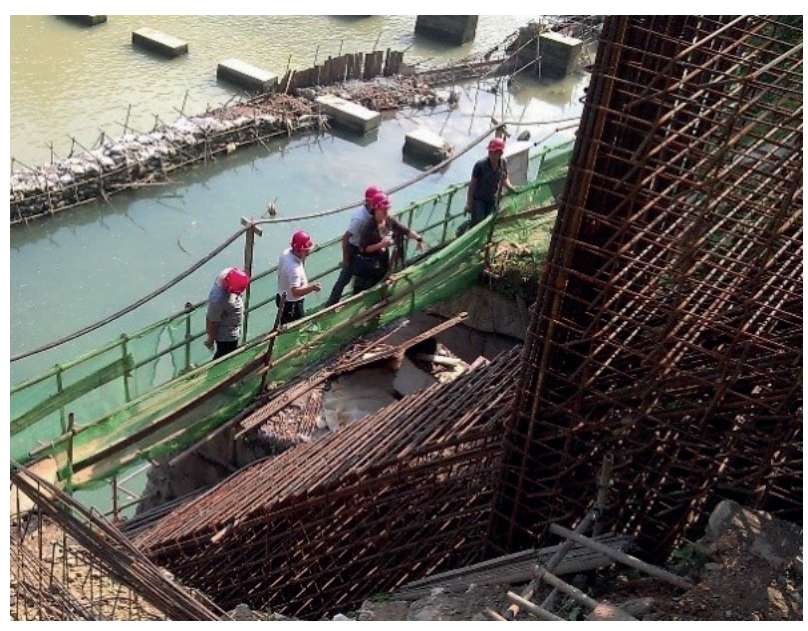

(b)

Fig. 15 Photographs form the construction site: (a) Excavation of the pit; (b) Reinforcement arrangement of the structure the deformation and stress of the supporting and retaining structure during the construction and operation of the office building (Fig. 16(a)). The displacement measuring points AP1 and AP2 on the top of the anti-sliding pile are measured by total station. Four earth pressure gauges named EG1, EG2, EG3 and EG4 are arranged in B4 supporting and retaining structure for measuring the contact pressure of different parts of retaining structure. The arrangement is shown in Fig. 16(b), and direction of it is indicated by arrows. In addition, two ground displacement measuring points named ST1 and ST2 are arranged at the top of the slope corresponding to B4 and B12 supporting and retaining structures, respectively. The deformation of the supporting and retaining structure is monitored after the pouring. The value of the earth pressure gauge is recorded when the strength of the supporting and retaining structure reaches $80 \%$ of the design value. The ground displacement monitoring on the top of the slope starts before the excavation of the supporting and retaining structure foundation pit.

As shown in Fig. 17, ST1H is the horizontal displacement of the slope measuring point ST1, and ST1V is the vertical one. It can be seemed that the horizontal displacement of the slope fluctuated between $0-5.22 \mathrm{~mm}$, and the vertical one fluctuated between $-0.04-5.00 \mathrm{~mm}$. Indicate that the slope is in a safe state. And the maximum horizontal displacement of the pile top is $4.42 \mathrm{~mm}$ at the AP1, the maximum vertical displacement is $-3.79 \mathrm{~mm}$. As shown in Fig. 17(c), the maximum internal force of the supporting and retaining structure is $-0.17 \mathrm{kPa}$ at the EG2, which is

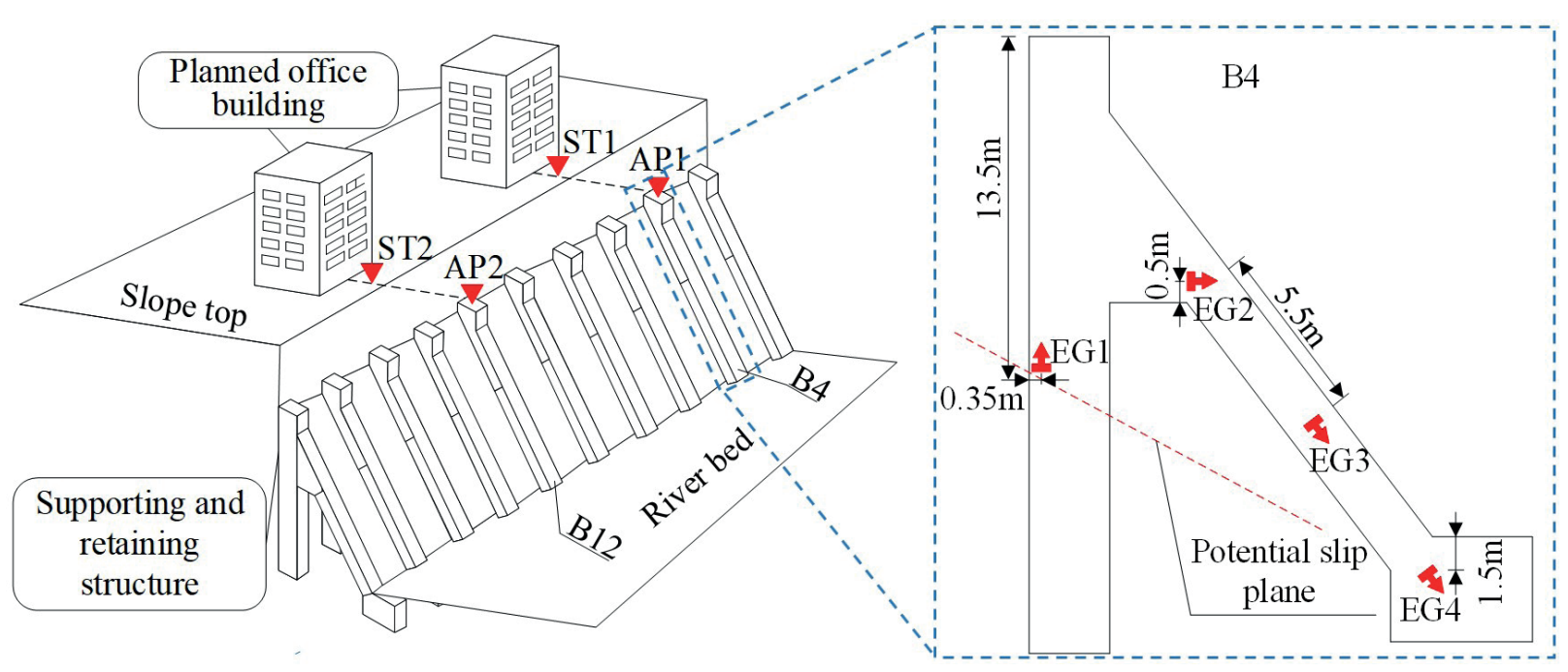

(a)

(b)

Fig. 16 Arrangement of the measuring points: (a) Displacement measuring points; (b) Pressure measuring points 


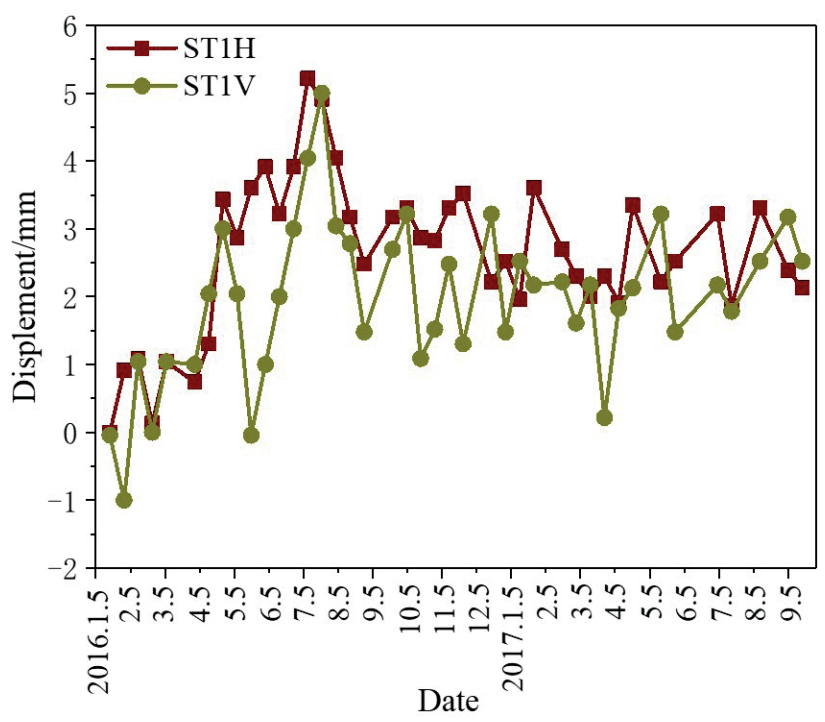

(a)

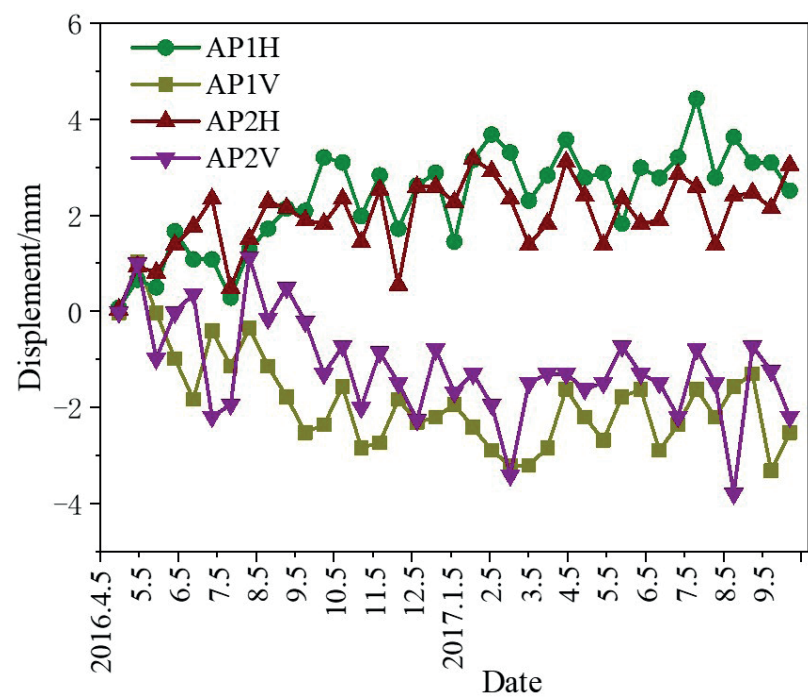

(b)

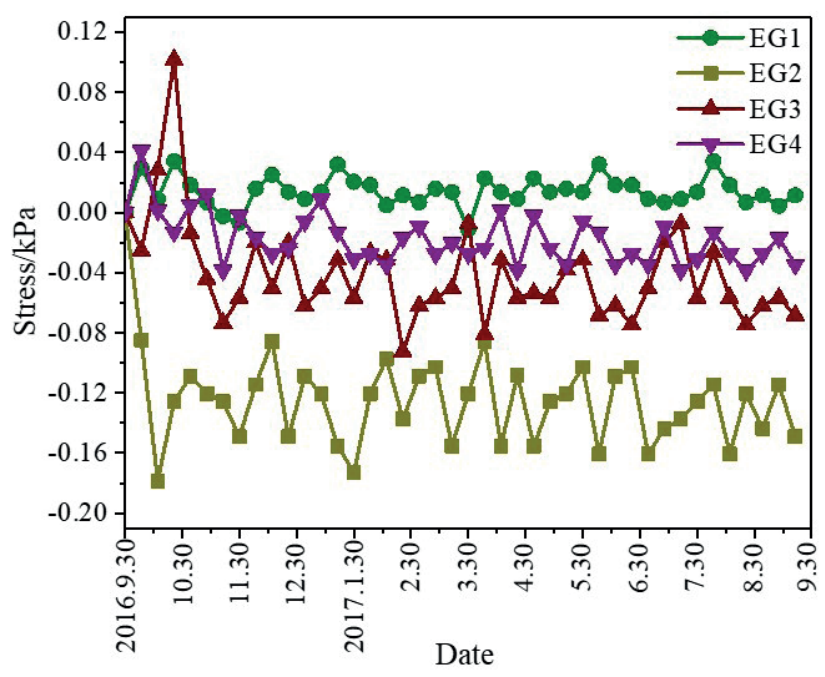

(c)

Fig. 17 Displacement-time curve: (a) Displacement of the slope; (b) Displacement of the pile top; (c) Internal force-time curve far less than the design value. The strength of the supporting and retaining structure meets the requirements and the structure is in a safe state.

\section{Conclusions}

This paper proposed a novel supporting and retaining structure used to high-steep building slope reinforcement. Furthermore the mechanical characteristics of the novel supporting and retaining structure are studied by two mechanical methods and two numerical methods, respectively. Then, the mechanical characteristics of each analysis result are compared and discussed. Based on the study results, the design internal force and structural reinforcement of supporting and retaining structure are determined. Finally, the novel supporting and retaining structure is applied in the field, and the application effect is verified by the field monitoring. Some rules are drawn as follows:

1. The novel supporting and retaining structure combined with an anti-sliding pile and an inclined supporting column, the thrust is transmitted to the riverbed by the supporting column. Therefore, the anti-sliding pile can bear more thrust force and the deformation and rotation of the pile top are limited by the resistance of the supporting column. Moreover, the inclined supporting column is constructed outside slope to avoid the influence of anchor cable inside slope on building pile foundation, and it is facilitated maintenance. Calculation results show that it has good mechanical characteristics. And monitoring data show it is effective for the reinforcement of the high-steep building slope.

2. Mechanical characteristics of the novel supporting and retaining structure based on these four methods are basically shown the same features. The supporting column will bear a large axial pressure under the sliding thrust, and the axial force will be evenly distributed along the column body. Meanwhile, it can provide a quite resistant force to the anti-sliding pile. Whereas, there are two shear force concentrated areas of the anti-sliding pile, one is from the top of the embedded area of the pile body to the potential slip plane, the other is at the joint.

3. The internal force of the supporting and retaining structure calculated by the 2D numerical model 1 is basically the same as that calculated by the force method. However, a large shear force and moment will be caused at the restrained end of the pile body by the force method and 2D numerical model 1. For the embedded area is simplified as a fixed constraint, the resistance force will resist rotation of the cantilever area. 
4. Because of neglecting the vertical component of the sliding thrust in Wenkler model, the internal force of the pile obtained by Wenkler model and 2D numerical model 2 are different from value, but the internal force distribution characteristics are consistent.

5. The constraint of pile bottom is regarded as a fixed hinge support, which can rotate by the Wenkler model and the 2D numerical model 2. For the rock in the embedded area is non-rigid, the anti-sliding pile will produce a certain amount of deflection under the sliding thrust, which reduces the shear force and moment at the top of the

\section{References}

[1] Deng, G., Xu, T., Chen, R., Lu, Z., Liu, J. "Numerical Analysis on Stabilizing Mechanism of Soil Nails in Steep Fill Slopes Subjected to Rainfall Infiltration Using a Hypoplastic Model", Arabian Journal for Science and Engineering, 43, pp. 5079-5090, 2018. https://doi.org/10.1007/s13369-017-2937-9

[2] Hadji, R., Rais, K., Gadri, L., Chouabi, A., Hamed, Y. "Slope Failure Characteristics and Slope Movement Susceptibility Assessment Using GIS in a Medium Scale: A Case Study from Ouled Driss and Machroha Municipalities, Northeast Algeria", Arabian Journal for Science and Engineering, 42, pp. 281-300, 2017. https://doi.org/10.1007/s13369-016-2046-1

[3] Yin, Z., Liu, X., Yang, Z., Jiang, Y., Zhao, Y., Li, S. "Shear Characteristics and Failure Mode of Hard Brittle Marl with Parallel Discontinuous Structural Plane", Arabian Journal for Science and Engineering, 45, pp. 8219-8229, 2020. https://doi.org/10.1007/s13369-020-04674-5

[4] Abramson, L. W., Thomas, S. L., Sunil, S., Glenn, M. B. "Slope stability and stabilization methods", Wiley, New York, NY, USA, 2002.

[5] Kim, C., Kwon, J., Im, J.-C., Hwang, S. "A method for analyzing the self-supported earth-retaining structure using stabilizing piles", Marine Georesources \& Geotechnology, 30(4), pp. 313-332, 2012. https://doi.org/10.1080/1064119X.2011.626669

[6] Zhao, B., Wang, Y.-S., Wang, Y., Shen, T., Zhai, Y.-C. "Retaining mechanism and structural characteristics of $h$ type anti-slide pile (hTP pile) and experience with its engineering application", Engineering Geology, 222, pp. 29-37, 2017. https://doi.org/10.1016/j.enggeo.2017.03.018

[7] Sun, Z., Kong, L., Guo, A., Xu, G., Bai, W. "Experimental and numerical investigations of the seismic response of a rock-soil mixture deposit slope", Environmental Earth Sciences, 78, Article number: 716, 2019. https:/doi.org/10.1007/s12665-019-8717-y

[8] Wu, R., Zhang, Y., Guo, C., Yang, Z., Tang, J., Su, F. "Landslide susceptibility assessment in mountainous area: a case study of Sichuan-Tibet railway, China", Environmental Earth Sciences, 79, Article number: 157, 2020. https://doi.org/10.1007/s12665-020-8878-8

[9] Xue, D., Li, T., Wei, Y., Gao, M. "Mechanism of reactivated Badu landslide in the Badu Mountain area, Southwest China", Environmental Earth Sciences, 73, pp. 4305-4312, 2015. https://doi.org/10.1007/s12665-014-3714-7 embedded area of the pile body. Besides, the moment in the middle part of the pile body are increased.

\section{Acknowledgements}

The project presented in this article is supported by the National Natural Science Foundation of China (No. 41772319), the National Natural Science Foundation of China (No. 41972266) and the Graduate Scientific Research and Innovation Foundation of Chongqing, China (Grant No. CYS20023)

[10] Lődör, K., Szendefy, J., Kovács, O., Illés, Z. "Development of a Reinforced Concrete Sheet Pile Wall Element", Periodica Polytechnica Civil Engineering, 64(2), pp. 623-630, 2020. https://doi.org/10.3311/PPci.15515

[11] Buslov, A., Margolin, V. "The influence of the second row of piles in double-row pile retaining walls with the stabilization of landslide", IOP Conference Series: Materials Science and Engineering, 365(5), Article number: 52006, 2018. https://doi.org/10.1088/1757-899X/365/5/052006

[12] Ito, T., Matsui, T., Pyo, H., Wong, W. P. "Design method for stabilizing piles against landslide: one row of piles", Soils and Foundations, 21(1), pp. 21-37, 1981. https://doi.org/10.3208/sandf1972.21.21

[13] Jeong, S., Kim, B., Won, J., Lee, J. "Uncoupled analysis of stabilizing piles in weathered slopes", Computers and Geotechnics, 30(8), pp. 671-682, 2003. https://doi.org/10.1016/j.compgeo.2003.07.002

[14] Kourkoulis, R., Gelagoti, F., Anastasopoulos, I., Gazetas, G. "Slope Stabilizing Piles and Pile-Groups: Parametric Study and Design Insights", Journal of Geotechnical and Geoenvironmental Engineering, 137(7), pp. 663-677, 2011. https://doi.org/10.1061/(ASCE)GT.1943-5606.0000479

[15] Shen, Y., Yu, Y., Ma, F., Mi, F., Xiang, Z. "Earth pressure evolution of the double-row long-short stabilizing pile system", Environmental Earth Sciences, 76, Article number: 586, 2017. https://doi.org/10.1007/s12665-017-6907-z

[16] Li, C., Chen, W., Song, Y., Gong, W., Zhao, Q. "Optimal Location of Piles in Stabilizing Slopes Based on a Simplified Double-Row Piles Model", KSCE Journal of Civil Engineering, 24, pp. 377-389, 2020 . https://doi.org/10.1007/s12205-020-0712-Z

[17] Zhang, H., Li, C., Yao, W., Long, J. "A Novel Approach for Determining Pile Spacing considering Interactions among Multilayered Sliding Masses in Colluvial Landslides", KSCE Journal of Civil Engineering, 23, pp. 3935-3950, 2019. https://doi.org/10.1007/s12205-019-0459-6

[18] Movahedi Rad, M. "Reliability Based Analysis and Optimum Design of Laterally Loaded Piles", Periodica Polytechnica Civil Engineering, 61(3), pp. 491-497, 2017. https://doi.org/10.3311/PPci.8756 
[19] Bekbasarov, I., Shanshabayev, N. "Impact Dipping PyramidalPrismatic Piles and their Resistance to Pressure and Horizontal Load", Periodica Polytechnica Civil Engineering, 65(3), pp. 909917, 2021. https://doi.org/10.3311/PPci.17923

[20] Tang, H., Hu, X., Xu, C., Li, C., Yong, R., Wang, L. "A novel approach for determining landslide pushing force based on landslide-pile interactions", Engineering Geology, 182(A), pp. 15-24, 2014.

https://doi.org/10.1016/j.enggeo.2014.07.024

[21] Zhou, C., Shao, W., van Westen, C. J. "Comparing two methods to estimate lateral force acting on stabilizing piles for a landslide in the Three Gorges Reservoir China", Engineering Geology, 173, pp. 41-53, 2014. https://doi.org/10.1016/j.enggeo.2014.02.004

[22] Kong, Y., Ruan, H., Huang, X., Zhu, Z. "Field Testing of Earth Pressures in a Large-scale Natural Loess Slope", KSCE Journal of Civil Engineering, 22, pp. 2266-2273, 2018. https://doi.org/10.1007/s12205-017-0339-х

[23] Huang, Y., Xu, X., Mao, W. "Numerical performance assessment of slope reinforcement using a pile-anchor structure under seismic loading", Soil Dynamics and Earthquake Engineering, 129, Article number: 105963, 2020.

https://doi.org/10.1016/j.soildyn.2019.105963

[24] Galli, A., di Prisco, C. "Displacement-based design procedure for slope-stabilizing piles", Canadian Geotechnical Journal, 50(1), pp. 41-53, 2013.

https://doi.org/10.1139/cgj-2012-0104

[25] Xiao, S., Zeng, J., Yan, Y. "A rational layout of double-row stabilizing piles for large-scale landslide control", Bulletin of Engineering Geology and the Environment, 76, pp. 309-321, 2017. https://doi.org/10.1007/s10064-016-0852-z

[26] Huang, C., Ren, W., Kong, L. "New mathematical modeling of stabilizing pile with prestressed tieback anchors", Mathematical Problems in Engineering, 2013, Article ID 601508, 2013. https://doi.org/10.1155/2013/601508

[27] Wu, R., Zhou, H., Hu, Y., Zhong, Y., Li, P., Yang, J. "An improved method for calculating anti-sliding pile with prestressed anchor cable based on finite difference theory", Rock and soil Mechanics, 36(6), pp. 1791-1800, 2015. (in Chinese) https://doi.org/10.16285/j.rsm.2015.06.034
[28] Usluogullari, O. F., Temugan, A., Duman, E. S. "Comparison of slope stabilization methods by three-dimensional finite element analysis", Natural Hazards, 81, pp. 1027-1050, 2016. https://doi.org/10.1007/s11069-015-2118-7

[29] Wang, Y. "Calculation theory and design method research on h-type of anti-sliding piles", PhD Thesis, Chengdu University of Technology, 2011.

[30] Gan, F., Ye, X., Yin, K., Li, M., Bi, J. "Analysis of Stress Characteristics and the Engineering Application of the SelfBalancing Retaining Wall", Advances in Materials Science and Engineering, 2017, Article ID 2463735, 2017. https://doi.org/10.1155/2017/2463735

[31] Zhang, Y., Zhou, H., Feng, X., Wang, G., Li, S. "Simplified calculation method and affecting factors analysis of h-type anti-slide pile", Chinese Journal of Rock Mechanics and Engineering, 35(S1) pp. 2935-2943, 2016. (in Chinese) https://doi.org/10.13722/j.cnki.jrme.2015.0701

[32] Liu, X.-R., Kou, M.-M., Feng, H., Zhou, Y. "Experimental and numerical studies on the deformation response and retaining mechanism of h-type anti-sliding piles in clay landslide", Environmental Earth Sciences, 77, Article number: 163, 2018. https://oi.org/10.1007/s12665-018-7360-3

[33] Qiao, S., Xu, P., Teng, J., Sun, X. "Numerical Study of Optimal Parameters on the High Filling Embankment Landslide Reinforced by the Portal Anti-Slide Pile", KSCE Journal of Civil Engineering, 24, pp. 1460-1475, 2020. https://doi.org/10.1007/s12205-020-1743-1

[34] National Standards of P.R.C. "Technical code for building slope engineering in China", National Standards of People's Republic of China, Beijing, China, 2013. (in Chinese)

[35] LIZHENG "Series Software of Lizheng Geological Structure Designing", Beijing Lizheng Software Design Institute Co., Ltd., Beijing, China.

[36] Peng, W. B., Zhao, Q. L., Pan, X. D., Xiong, Z. H. "Study of calculation for internal force of complex bridge sections using solid elements", Chinese Journal of Civil Engineering, 45(9), pp. 91-99, 2012. (in Chinese) https://doi.org/10.15951/j.tmgcxb.2012.09.009 